\title{
Numerical modelling and fire design of stainless steel hollow section columns
}

\author{
A. Mohammed ${ }^{\mathrm{a}}$ and S. Afshan ${ }^{\mathrm{b} *}$ \\ ${ }^{\text {a }}$ Brunel University London, London, UK \\ b* University of Southampton, Southampton, UK
}

Corresponding author E-mail: s.afshan@soton.ac.uk

\section{Abstract}

In this paper, the elevated temperature buckling performance and design of cold-formed square, rectangular and circular hollow section columns made of stainless steel is studied through a numerical modelling investigation. The finite element analysis software Abaqus was employed to perform the simulations, where the validity of the models was established by replicating the results of flexural buckling tests at both elevated and room temperatures from literature test programmes. In total, twelve square (SHS) and rectangular (RHS) hollow section columns tested at elevated temperature and eleven circular (CHS) hollow section columns tested at room temperature were simulated. Following this, a comprehensive numerical parametric investigation was performed to systematically assess the effect of variation of the governing parameters including the grade of stainless steel (austenitic, duplex and ferritic) and the elevated temperature member slenderness $\left(\bar{\lambda}_{\theta}=0.1-2.0\right)$ for all considered cross-section shapes with the addition of the aspect ratio of the cross-section $(\mathrm{h} / \mathrm{b}=1.0$ and 1.5$)$ and the column axis of buckling (major and minor) for the SHS and RHS. The applicability and accuracy of the design methods recommended in EN 1993-1-2 and the Design Manual for Stainless Steel Structures were carefully assessed on the basis of the numerical flexural buckling performance results. New buckling formulations for the fire design of cold-formed stainless steel SHS/RHS and CHS columns were proposed, and their suitability was confirmed by means of reliability analysis.

Keywords: Column buckling; Fire design; Numerical modelling; Reliability analysis; Stainless steel.

\section{Introduction}

The resistance to corrosion and durability of stainless steel materials are well known, offering the potential for more sustainable construction with increased structural design lives. Stainless steel is most commonly used in structures in the offshore and onshore industrial sector (e.g. Oil and Gas, Petrochemical, Pharmaceutical, nuclear, etc.) where fire is a significant hazard. Other applications where stainless steel has to demonstrate fire resistance are in light interior structures (e.g. escape routes in airports and office buildings), safety critical structures (e.g. locations 
exposed to terrorist attack) and fastening systems. Stainless steel in tunnels, where the presence of the corrosive environment coupled with the high maintenance costs necessitates the use of highly durable materials, is also an important environment for fire resistance. Hence, development of design guidance that is both accurate and economic is of paramount importance when stainless steel is used in fire safety critical applications. The improved fire resistance displayed by structural members made of stainless steel compared to carbon steels have been shown by a number of recent research programmes e.g. in [1-3]. This is mainly associated with the ability of stainless steel materials, in particular the austenitic and duplex grades, to retain higher portions of their strength, both yield strength $f_{\mathrm{y}}$ and ultimate tensile strength $f_{\mathrm{u}}$, as well as stiffness $E$ at elevated temperatures [4-5], in comparison with carbon steels, which in turn lead to improved fire performance at structural level.

Guidelines for the fire resistant analysis and design of carbon steel structural members and assemblies is supplied by Eurocode 3 specifications including mainly EN 1993-1-2 [6]. EN 19931-4 [7], which is the Eurocode 3 part with supplementary design guidelines for structures made of stainless steels, makes reference to the guidelines in EN 1993-1-2 [6] for their fire design, where the same recommendations as those for carbon steels, but in conjunction with the stiffness and strength reduction factors for stainless steel material, are also adopted for stainless steels. However, the highly nonlinear stress-strain response of stainless steels, with no clearly defined yield strength and substantial strain-hardening compared to carbon steels, have been shown to have a direct effect on their structural behaviour and consequently different design rules, which are developed and verified for stainless steels, will be required in certain cases.

This paper is focused on the flexural buckling performance and fire resistance design of columns made of stainless steel with square (SHS), rectangular (RHS) and circular (CHS) hollow sections produced by cold-forming. A comprehensive numerical modelling investigation is conducted in order to generate flexural buckling performance data for stainless steel axially loaded members under elevated temperatures. The development of the finite element models together with their validation on the basis of physical experiments in fire from the literature are described in detail. The results of the subsequently carried out parametric study are presented and detailed comparisons between the FE generated buckling resistances and the predictions based on the guidelines in existing specifications - EN 1993-1-2 [6] and the Design Manual for Structural Stainless Steel [8] are made. Finally, a fire buckling design method, in line with the numerical results obtained, is proposed, and reliability analysis are carried out. 


\section{Numerical models - development and validation}

The finite element analysis package ABAQUS [9] was employed. The numerical modelling investigation involved two stages; these comprised the validation of the finite element models using the results of column tests from literature test programmes reported in $[1,10,11]$ for SHS and RHS at elevated temperature and in $[12,13]$ for CHS at room temperature, which is described in Section 2, and the generation of additional column flexural buckling performance data through a parametric study, which is presented in Section 3.

\subsection{Summary of literature tests}

The key details of the elevated temperature tests on SHS and RHS columns carried out by Tondini et al. [1], Ala-Outinen and Oksanen [10] and Baddoo and Gardner [11], including stainless steel grade, boundary conditions, measured column length $L$, applied load and critical temperature $\theta_{\text {crit }}$ are reported in Table 1 and those for the room temperature tests on CHS columns performed by and reported in Zhao et al. [12] and Buchanan et al. [13] are presented in Table 2, where in addition, the measured ultimate load $N_{\mathrm{u}}$ is reported. The SHS and RHS columns tested in [1] and [10] were formed by cold-forming, where the sheet material was first made into a circular tube by cold-rolling and closed by seam-welding and then made into the required cross-section size and geometry. For the RHS columns tested in [11], two channel sections, formed by press-braking, were welded tip-to-tip in the longitudinal direction. The CHS columns tested in $[12,13]$ were also cold-formed, where the sheet material was cold-rolled into a circular tube and subsequently welded closed.

Anisothermal fire test method was employed for all the SHS and RHS axially loaded members presented in Table 1, where the specimens were first loaded at ambient temperature, which was kept constant, and then the temperature was set to increase until the failure was reached at temperature $\theta_{\text {crit. }}$ The critical temperature $\theta_{\text {crit }}$ reported in Table 1 refers to the specimen temperature at failure for the austenitic columns tested in $[10,11]$ and the furnace temperature at failure for the ferritic columns tested in [1]. The models of these columns involved a sequentially coupled thermal-stress analysis with three types of numerical analyses as described hereafter. Firstly, buckling eigenmodes were obtained from an eigenvalue buckling prediction analysis, based on which, geometric imperfections consisting superimposed buckling modes representing the deformed geometry of the modelled columns at both local (cross-section) and global (member) levels were introduced into the models. Heat transfer analysis was used to model heat conduction with radiation and convection boundary conditions to obtain the time-temperature development field of the heated columns when subjected to furnace temperature. Finally, a stress analysis to 
determine the member response under the application of load and temperature was performed. For the room temperature CHS columns presented in Table 2, a nonlinear stress analysis (accounting for both material and geometric nonlinearities), with initial geometric imperfections obtained from an elastic eigenvalue buckling analysis, was carried out.

\subsection{Thermal and stress models of the elevated temperature tests}

The measured specimen temperature-time data were utilised in the numerical models developed for the austenitic EN 1.4301 columns tested in $[10,11]$. The specimen temperature-time was not measured for the ferritic EN 1.4003 columns tested in [1]; the furnace temperature was only measured. Therefore, for these columns, thermal analysis models were first developed, where the measured furnace temperature-time was applied to the exposed surface of the columns and convection, radiation and conduction heat transfer mechanisms were carefully simulated to obtain the temperature rise in the member. Radiation was modelled as surface radiation with using the command *SRADIATE in ABAQUS with the emissivity coefficient taken as 0.4 from EN 19931-2 [6]. Convection was modelled as a film condition using the command *SFILM in ABAQUS with the coefficient for the convective heat transfer taken as $25 \mathrm{~W} / \mathrm{m}^{2} \mathrm{~K}$ as specified in EN 19931-2 [6]. Other required physical properties for the thermal model included the temperature dependent specific thermal capacity $(c)$, thermal conductivity $(\lambda)$ and thermal expansion - these were obtained from Clauses 8.4.1, 8.4.2 and 8.4.3, respectively of the Design Manual for Stainless Steel Structures (DMSS) [8]. The developed thermal models were capable of reproducing the temperature development of the stainless steel specimens accurately as shown in Figure 1.

In order to simulate the loading and heating conditions of the tested columns, the geometrically and materially nonlinear stress analysis was carried out in two steps. A static compressive concentric load, of equal magnitude to the test loads, was first applied to the modelled columns at ambient temperature. In the subsequent step, the applied compressive load was then sustained at the same level during which the increase in the specimen temperature over the heating time was applied from the heat transfer models. The measured specimen temperature-time curves from the tests were directly imported into the FE models of the austenitic columns.

\subsection{General modelling assumptions}

To model the stainless steel SHS, RHS and CHS columns, shell elements were employed herein as it is commonly used in similar models of structural components made of thin-walled crosssections [2-3, 14]. The general-purpose four-noded three-dimensional shell element S4R [9] with reduced integration was utilised for the stress analysis part of the models developed herein. For the thermal models of the SHS and RHS columns, the DS4 [9] element, which is compatible with 
S4R element, were employed. An element mesh size of minimum ten elements across each plate was used to discretise the sections; this was found from a mesh sensitivity analysis to be a suitable mesh size considering both the efficiency and accuracy of the simulations. The displacement and rotation end conditions of the modelled columns were appropriately defined to simulate the pinned end and fixed end support conditions of the tested columns presented in Tables 1 and 2. The geometric dimensions of the columns as measured in the tests were utilised in the FE models to replicate the corresponding test specimens.

\subsection{Material modelling}

In the test programme by Baddoo and Gardner [11], the elevated temperature stress $\left(\sigma_{\theta}\right)$-strain $\left(\varepsilon_{\theta}\right)$ responses for the unformed material sheets from which the channel sections were fabricated by press-braking was measured by conducting isothermal tests at $\theta=20-1000{ }^{\circ} \mathrm{C}$. Ala-Outinen and Oksanen [10] conducted tensile anisothermal tests on the material belonging to the flat parts of the cold-rolled hollow sections; these were subsequently converted to stress $\left(\sigma_{\theta}\right)$-strain $\left(\varepsilon_{\theta}\right)$ relationships at discrete temperatures in the range of $\theta=20-900{ }^{\circ} \mathrm{C}$. Hence, for these columns $[10,11]$, the measured elevated temperature stress $\left(\sigma_{\theta}\right)$-strain $(\varepsilon \theta)$ responses were used to describe the material behaviour for the flat parts of the SHS and RHS columns in the developed FE models.

For the case of the SHS and RHS ferritic columns [1], the two-stage elevated temperature Ramberg-Osgood material model recommended in the Design Manual for Stainless Steel Structures [8] as given by Eqs (1) and (2) was employed to construct full range stress $(\sigma \theta)$-strain $(\varepsilon \theta)$ relationships at temperatures $\theta=20-800{ }^{\circ} \mathrm{C}$. The improved accuracy and the ease of use of the two-stage elevated temperature Ramberg-Osgood material model, employed herein, over the model provided in EN 1993-1-2 [6] was demonstrated by Gardner et al. [15]. The reduction factors pertaining to grade EN 1.4003 provided in [8] together with the room temperature material properties measured in the tests were used. These were used to describe the material behaviour of the flat portions of these columns in the developed FE models. In Eqs (1) and (2), $f_{0.2, \theta}, E_{\theta}, f_{\mathrm{u}, \theta}, f_{2, \theta}$ are the $0.2 \%$ proof stress, the Young's modulus, the ultimate tensile stress and the stress at $2 \%$ total strain at temperature $\theta$, respectively, $E_{0.2, \theta}$ is the tangent modulus at $f_{0.2, \theta}, \varepsilon_{0.2, \theta}$ is the total strain at $f_{0.2, \theta}, \varepsilon_{\mathrm{u}, \theta}$ is the strain at $f_{\mathrm{u}, \theta}$ and $n_{\theta}$ and $m_{\theta, 2}$ are the Ramberg-Osgood model parameters at temperature $\theta$.

$$
\varepsilon_{\theta}=\frac{\sigma_{\theta}}{E_{\theta}}+0.002\left(\frac{\sigma_{\theta}}{f_{0.2, \theta}}\right)^{n_{\theta}} \text { for } \sigma_{\theta} \leq f_{0.2, \theta}
$$




$$
\varepsilon_{\theta}=\frac{\sigma_{\theta}-f_{0.2, \theta}}{E_{0.2, \theta}}+\left[0.02-\varepsilon_{0.2, \theta}-\frac{f_{2, \theta}-f_{0.2, \theta}}{E_{0.2, \theta}}\right]\left(\frac{\sigma_{\theta}-f_{0.2, \theta}}{f_{2, \theta}-f_{0.2, \theta}}\right)^{m_{\theta, 2}}+\varepsilon_{0.2, \theta} \text { for } f_{0.2, \theta}<\sigma_{\theta} \leq f_{\mathrm{u}, \theta}
$$

For the corner portions of the SHS and RHS columns, their enhanced strength, associated with cold-forming effects, was included in the FE models as described hereafter. For the ferritic columns, the room temperature corner material properties were measured. For the austenitic columns, the material properties for the corner regions of the sections were not measured, and hence the strength enhancement predictive equations from Cruise and Gardner [16] for cold-rolled and press-braked stainless steel sections were employed to determine the room temperature strengths. Eqs (1) and (2) in conjunction with the reduction factors for EN 1.4301 and EN 1.4003 from the Design Manual for Stainless Steel Structures [8] for material with enhanced cold-form strength were employed to construct continuous stress $\left(\sigma_{\theta}\right)$-strain $(\varepsilon \theta)$ relationships to describe the material behaviour of the cold-worked corner regions at elevated temperatures.

For the room temperature CHS column tests reported in $[12,13]$, reported values from tensile coupon tests on materials cut from the cold-formed sections were used to obtain the stress-strain response of the material, which were directly used in the development of the FE models of the CHS columns.

In ABAQUS, the material behaviour was modelled as elastic-plastic with a von Mises yield criterion and isotropic hardening. ABAQUS requires that for shell elements the input material stress-strain curves are described as multi-linear true stress $\left(\sigma_{\text {true }}\right)$ and logarithmic plastic strain $\left(\varepsilon_{\ln }^{\mathrm{pl}}\right)$ responses, which may be obtained from the engineering stress $\left(\sigma_{\text {nom }}\right)$ and strain $(\varepsilon$ nom $)$ as presented in Eqs (3) and (4), where $E$ is the Young's modulus.

$$
\begin{gathered}
\sigma_{\text {true }}=\sigma_{\text {nom }}\left(1+\varepsilon_{\text {nom }}\right) \\
\varepsilon_{\ln }^{\mathrm{pl}}=\ln \left(1+\varepsilon_{\text {nom }}\right)-\frac{\sigma_{\text {true }}}{E}
\end{gathered}
$$

\subsection{Modelling of imperfections}

The models included initially imperfect geometries corresponding to the most likely instability modes, which for columns with thin-walled SHS, RHS and CHS cross-sections can be local, global or both. Suitable buckling eigenmodes extracted from the eigenvalue buckling prediction analysis were selected to represent the local and global imperfection patterns of the modelled columns. The amplitudes of the global imperfections were set to the measured values in the tests; except for the elevated temperature tests conducted in $[10,11]$, for which a value of $L / 1000,(L=$ 
columns length), gave the closest agreement between the responses from test and FE. In the absence of the measured values, the local imperfection amplitudes were set to a portion of the thickness of the cross-section $(t / 10)$ for the CHS models, as recommended in [17], and those obtained from the modified Dawson and Walker predictive model [18], as given by Eq. (5), for the SHS and RHS columns, where $t$ is the thickness of the cross-section, $f_{0.2}$ is the $0.2 \%$ proof stress and $f_{\text {cr }}$ is the plate element buckling stress. The typical membrane and bending residual stresses associated with structural sections made of cold-formed stainless steel were not defined in the developed numerical models in an explicit manner, as the inclusion of membrane residual stresses has been shown to have little effect on the structural behaviour, while the effect of bending residual stresses is already present in the measured stress-strain relationships employed [12-14, 17].

$$
\omega_{0}=0.023 t f_{0.2} / f_{\text {cr }}
$$

\subsection{Validation results}

The modelling procedures described were applied to replicate the test responses of the stainless steel columns reported in Tables 1 and 2. Two performance criteria for structural members subjected to vertical loads at elevated temperatures, which are related to the magnitude of the vertical contraction $(\Delta L)$ and the vertical contraction rate $(\Delta L / \Delta T)$, are specified in EN 1363 [19] to mark their critical failure temperature in fire. According to these criteria, the failure temperature is specified as that at which the vertical contraction and the rate of vertical contraction reach their limiting values $-(\Delta L)_{\text {limit }}=L / 100(\mathrm{~mm})$ and $(\Delta L / \Delta T)_{\text {limit }}=3 L / 1000(\mathrm{~mm} / \mathrm{min})$, respectively. The failure temperatures of the simulated columns were specified by applying the EN 1363 [19] criteria explained above, which were compared with the failure test temperatures determined by the same manner.

Figures 2 (a)-(c) compare the axial displacement-temperature responses from the tests and FE for the SHS $80 \times 80 \times 3-2500$, SHS $40 \times 40 \times 4-T 5$ and RHS $150 \times 75 \times 6$ columns, respectively. It should be noted that the temperatures in Figure 1 (a) refer to the furnace temperature for both the tests and the FE models and those in Figures 1 (b) and (c) are the specimen temperatures to enable a like for like comparison of the observed and modelled responses.

The axial displacement-temperature response of the axially loaded compression members at elevated temperatures begins with an initial shortening when the compressive load is applied at room temperature, which is then followed by increasing axial expansion with the temperature rise. The rate of increase in the axial thermal expansion however decreases at higher temperatures as 
the column stiffness reduces and the mechanical shortening, due to the combination of axial shortening and the out-of-plane lateral deflection from column buckling, becomes important. The column reaches a limiting point where it starts to contract as the mechanical shortening overtakes the thermal expansion, and the applied compressive load cannot be supported. Since the mechanical shortening of the column is controlled by the tangent stiffness of the material at elevated temperature, which reduces very rapidly, the final stage of the response is rather abrupt. The FE models were capable of accurately replicating these experimentally observed stages of behaviour. Figures 3 (a)-(d) depict the test and FE responses in terms of the load versus midheight lateral deflection curves for the CHS 76.3×3, CHS 60.5×2.8, CHS 88.9×2.6-1650 and CHS $106 \times 3-3080$ columns, respectively. Comparison between the test and FE failure modes is depicted in Figure 4, where comparable results from both are observed.

The test and simulation critical temperature $\theta_{\text {crit }}$ comparison results for the elevated temperature SHS and RHS columns are presented in Table 3. The values for the mean and the coefficient of variation $(\mathrm{COV})$ of the $\mathrm{FE} /$ test critical temperatures for the modelled austenitic $[10,11]$ and ferritic [1] stainless steel columns are 0.90 and 0.03 and 1.00 and 0.02 , respectively. The comparison results for the test and FE room temperature CHS columns are presented in Table 4, where the FE to test ratios for the ultimate loads $\mathrm{N}_{u}$ and the mid-height lateral deflection at ultimate loads $\delta_{u}$ are reported. The mean and COV of the FE/test are 1.02 and 0.06 , respectively for $\mathrm{N}_{u}$ and 0.91 and 0.46 , respectively for $\delta_{u}$. The comparatively higher variation in the FE/test ratios of $\delta_{u}$ was also observed in numerical modelling simulations conducted by Buchanan et al. [13], and is expected due to the higher variability associated with displacements at ultimate loads of models of these structural members. Considering the high degree of accuracy obtained in predicting the flexural buckling response of the SHS/RHS columns at elevated temperatures and the CHS columns at room temperature, in terms of the axial displacement-temperature and loaddeformation response characteristics as well as the failure modes, the developed numerical modelling procedures described herein are validated and can reliably be adopted for performing numerical parametric investigations.

\section{Parametric study}

Parametric studies to examine the flexural buckling response of stainless steel columns with square, rectangular and circular hollow cross-section of different grades at elevated temperatures were carried out, the details of which are presented hereafter. For the purpose of the parametric study, the columns were modelled as isothermal, in which the stress-strain data corresponding to a given temperature $\theta$ were assigned to the FE models, akin to applying a uniform temperature $\theta$, 
and the compressive load applied was set to increase until failure was reached similar to the validated models of the room temperature tests. A static Riks method [9] was employed to solve the geometrically and materially nonlinear stress analysis problem from which the load versus deformation response of the columns and their failure loads were determined, which were used to derive buckling curves for their fire design as discussed in Section 4. This approach, which has been also adopted in other similar numerical modelling investigations e.g. in [2] and [20], was deemed acceptable, since the developed elevated temperature FE models did not explicitly include the effect of time dependent factors such as creep, i.e. creep effects were only implicitly included in the material properties/reduction factors of [8] derived from anisothermal tests, and as a result both the isothermal and anisothermal modelling approaches would yield very similar results.

The stress-strain response of stainless steels at room temperature differs for austenitic, duplex and ferritic grades as discussed in [17]. The degree of degradation of the mechanical properties with respect to temperature also vary amongst these grades. Hence, in order to study the effect of the different elevated temperature stress-strain response of the material on the flexural buckling capacity of compression members, the parametric study included austenitic, duplex and ferritic stainless steels. For each stainless steel grades considered, the varied parameters were the elevated temperature member slenderness $\left(\bar{\lambda}_{\theta}\right)$ for the SHS, RHS and CHS models as well as the aspect ratio of the cross-section $(h / b)$, where $h$ is the section height and $b$ is the section breadth, and the axis of buckling (major and minor) for the SHS and RHS models. For each of the cross-section dimensions and member lengths, the columns were modelled with four different temperatures in the range of $200^{\circ} \mathrm{C}$ to $800{ }^{\circ} \mathrm{C}$. The end support conditions of the columns were modelled as pinned at both ends, allowing free rotation about the designated member axis of buckling as well as free longitudinal displacement along the column length. All cross-sections were classified as fully effective in accordance with the EN 1993-1-2 [6] and EN 1993-1-4 [7] limits for classification of cross-sections at both room and elevated temperatures. Table 5 outlines the examined parameters for each of the cross-sections. The cross-section slenderness of the modelled columns, $\bar{\lambda}_{\mathrm{p}}$ and $\bar{\lambda}_{\mathrm{c}}$, are also included in Table 5, in which $\bar{\lambda}_{\mathrm{p}}$ is the plate slenderness of the SHS and RHS - as defined by Eq. (6) and $\bar{\lambda}_{\mathrm{c}}$ is the local slenderness of the CHS - as defined by Eq. (7). In Eq. (6), $f_{\text {cr,p }}$ is the elastic critical buckling stress of the plate element, $f_{2}$ is the stress at $2 \%$ total strain, which is the strength parameter used for fire design as discusses in more detail in Section $4, b$ and $t$ are the flat plate width and thickness, respectively, $E$ is the Young's modulus, $k_{\sigma}$ is the plate buckling coefficient, set to 4.0 for internal plate elements subjected to uniform compressive stress state and $v$ stands for the Poisson's ratio taken as 0.3. In Eq. (7), $f_{\mathrm{cr}, \mathrm{c}}$ is the elastic critical buckling stress for 
a circular hollow section, $D$ is the section outer diameter, and all other symbols are as previously defined. In total, 660 cold-formed stainless steel columns with SHS, RHS and CHS cross-section at elevated temperatures were modelled.

$$
\begin{gathered}
\bar{\lambda}_{\mathrm{p}}=\sqrt{\frac{f_{2}}{f_{\mathrm{cr}, \mathrm{p}}}}=\left(\frac{b}{t}\right)\left(\frac{f_{2}}{E}\right)^{0.5}\left(\frac{12\left(1-v^{2}\right)}{\pi^{2} k_{\sigma}}\right)^{0.5} \\
\bar{\lambda}_{\mathrm{c}}=\sqrt{\frac{f_{2}}{f_{\mathrm{cr}, \mathrm{c}}}}=\left(\frac{f_{2} D}{2 t E}\right)^{0.5}\left(\sqrt{3\left(1-v^{2}\right)}\right)^{0.5}
\end{gathered}
$$

The same modelling assumptions as explained in Section 2 were adopted in the models of the parametric study with the input parameters taken as those described hereafter. The room temperature material properties recommended by Afshan et al. [17] for austenitic, duplex and ferritic stainless steel cold-formed SHS, RHS and CHS, presented in Table 6, together with the required reduction factors pertaining to Austenitic I, Duplex II and Ferritic II grades provided in Table 8.1 of the Design Manual for Stainless Steel Structures [8] were employed; these are the most up to date set of reduction factors for stainless steel materials at elevated temperature. The two-stage Ramberg-Osgood material model, Eqs (1) and (2), was used to develop full-range stress-strain relationships for the modelled temperatures. The values for $n \theta$ were taken as the room temperature values for $n$ provided in [17] and the values for $m_{\theta, 2}$ were determined using Eq. (8); these are in accordance with the recommendations in Clause 8.5 of the Design Manual for Stainless Steel Structures [8].

$$
m_{\theta}=1+2.8 f_{0.2, \theta} / f_{\mathrm{u}, \theta}
$$

Similar to the validation models, the initial geometric imperfections were introduced as eigenmodes that were scaled to a suitable magnitude. The amplitudes for the global imperfection mode was set equal to the tolerance limit for fabrication, which is specified in EN 1090-2 [21] as $L / 1000$, where $L$ is the member length. For the local imperfection, for the SHS and RHS columns, the amplitude was set to $b / 200$, where $b$ is the section width and for the CHS columns, the amplitude was set to $0.008 D$, where $D$ is the diameter, in accordance with the recommendations in EN 1993-1-5 - Annex C [22]. Shell element S4R was selected to discretise the modelled crosssections; the element mesh size was equal to the thickness of the cross-sections $t$ for the CHS columns and the flat elements of the SHS and RHS columns which had a smaller mesh size of four elements in their corner portions to allow an accurate representation of the curved geometry. 


\section{Fire resistance design}

\section{EN 1993-1-2 method}

The design of structural elements and assemblies made of stainless steel in fire is covered in EN 1993-1-2 [6] with similar treatments as carbon steel structures. The response of steel structures in fire is typically accompanied by large deformations, and therefore in fire design, higher strain levels are considered acceptable compared to those at room temperature. For this reason, the strength parameter which the resistance of structural members, including columns, in fire is based on in EN 1993-1-2 is the stress at $2 \%$ total strain at elevated temperature $\theta$ i.e. $f_{2, \theta}=k_{2, \theta} f_{\mathrm{y}}$ for members with fully effective cross-sections (i.e. Class 1,2 and 3 ) and the $0.2 \%$ proof stress at elevated temperature $\theta$ i.e. $f_{0.2, \theta}=k_{0.2, \theta} f_{\mathrm{y}}$ for members with slender cross-section (i.e. Class 4 ), where $f_{\mathrm{y}}$ is the design yield strength at room temperature and $k_{2, \theta}$ and $k_{0.2, \theta}$ are the reduction factors for $f_{2, \theta}$ and $f_{0.2, \theta}$, respectively. These design strength parameters are also adopted in EN 1993-1-2 for the fire design of columns made of stainless steels, where the design yield strength at room temperature $f_{\mathrm{y}}$ is taken as the $0.2 \%$ proof stress.

The form of the flexural buckling curves provided in EN 1993-1-2 for the column design is the same as the flexural buckling curves for room temperature design set out in EN 1993-1-1 [23] for carbon steel and in EN 1993-1-4 [7] for stainless steel. The only exceptions are that there is no plateau i.e. $\bar{\lambda}_{0}=0$ and the imperfection factor $\alpha$ is expressed in terms of the yield strength $f_{\mathrm{y}}$ using $\alpha=0.65\left(235 / f_{\mathrm{y}}\right)^{0.5}$. In addition, the non-dimensional member slenderness at elevated temperature $\bar{\lambda}_{\theta}$, as defined by Eqs (9) and (10), is employed, in which $\bar{\lambda}$ is the column slenderness at room temperature, $k_{\mathrm{E}, \theta}$ is the reduction factor for Young's modulus $E_{\theta}$ at temperature $\theta$ and $k_{2, \theta}$ and $k_{0.2, \theta}$ are as previously defined. The non-dimensional buckling reduction factor $\chi_{\mathrm{fi}}$ as given by Eq. (11) is also recommended for stainless steel columns of all cross-section shapes.

$$
\begin{gathered}
\bar{\lambda}_{\theta}=\bar{\lambda}\left(\frac{k_{2, \theta}}{k_{\mathrm{E}, \theta}}\right)^{0.5} \text { for Class } 1,2 \text { and } 3 \text { cross-sections } \\
\bar{\lambda}_{\theta}=\bar{\lambda}\left(\frac{k_{0.2, \theta}}{k_{\mathrm{E}, \theta}}\right)^{0.5} \text { for Class } 4 \text { cross-sections } \\
\chi_{\mathrm{fi}}=\frac{1}{\varphi_{\theta}+\sqrt{\varphi_{\theta}^{2}-\bar{\lambda}_{\theta}^{2}}} \leq 1.0 \text { with } \varphi=0.5\left[1+\alpha \bar{\lambda}_{\theta}+\bar{\lambda}_{\theta}^{2}\right]
\end{gathered}
$$


Finally, the predicted flexural buckling resistance $N_{\mathrm{b}, \mathrm{fi}, \mathrm{t}, \mathrm{Rd}}$ of a compression member at time $t$ and experiencing a uniform temperature $\theta$ is obtained from Eqs (12) and (13), where $A$ is the crosssectional area for the gross cross-section, $A_{\text {eff }}$ is the cross-sectional area of the effective crosssection, $\gamma_{\mathrm{M}, \mathrm{fi}}$ is the member resistance partial resistance factor, which is 1.0 as set out in [6] and all other symbols are as previously defined.

$$
\begin{gathered}
N_{\mathrm{b}, \mathrm{fi}, \mathrm{t}, \mathrm{Rd}}=\frac{\chi_{\mathrm{fi}} A k_{2, \theta} f_{\mathrm{y}}}{\gamma_{\mathrm{M}, \mathrm{fi}}} \text { for Class } 1,2 \text { and } 3 \text { cross-sections } \\
N_{\mathrm{b}, \mathrm{fi}, \mathrm{t}, \mathrm{Rd}}=\frac{\chi_{\mathrm{fi}} A_{\mathrm{eff}} k_{0.2, \theta} f_{\mathrm{y}}}{\gamma_{\mathrm{M}, \mathrm{fi}}} \text { for Class } 4 \text { cross-sections }
\end{gathered}
$$

\section{Lopes et al. method}

Lopes et al. [20] conducted an extensive parametric numerical modelling investigation on axially loaded columns with welded stainless steel I-section in fire and proposed a modified version of the EN 1993-1-2 [6] flexural buckling curves. In the proposed buckling curves, (1) the parameter $\beta$ was introduced in the non-dimensional buckling reduction factor $\chi_{\mathrm{fi}}$ and $\varphi_{\theta}$ formulations as presented in Eq. (14) and (2) the imperfection parameter $\alpha$ was defined in terms of temperature $\theta$, as given by Eqs (15) and (16), which results in temperature dependant buckling curves. For welded I-section columns, $\beta$ values equal to 1.0 for major axis buckling and 1.5 for minor axis buckling, for all stainless steel grades were proposed. The $\alpha$ values were recommended as equal to 1.3 for austenitic (EN 1.4301, EN 1.4401, EN 1.4404 and EN 1.4571) and ferritic (EN 1.4003) grades and 0.9 for duplex (EN 1.4462) grade [20]. Using the proposed fire buckling curves and the same definition of $\bar{\lambda}_{\theta}$ given in Eqs (9) and (10), $N_{\mathrm{b}, \mathrm{fi}, \mathrm{t}, \mathrm{Rd}}$ may similarly be obtained from Eqs (12) and (13).

$$
\begin{gathered}
\chi_{\mathrm{fi}}=\frac{1}{\varphi_{\theta}+\sqrt{\varphi_{\theta}^{2}-\beta \bar{\lambda}_{\theta}^{2}}} \leq 1.0 \text { with } \varphi=0.5\left[1+\alpha \bar{\lambda}_{\theta}+\beta \bar{\lambda}_{\theta}^{2}\right] \\
\alpha=\eta \sqrt{\frac{235}{f_{\mathrm{y}}} \frac{E}{210000} \sqrt{\frac{k_{\mathrm{E}, \theta}}{k_{2, \theta}}} \text { for Class } 1,2 \text { and } 3 \text { cross-sections }} \\
\alpha=\eta \sqrt{\frac{235}{f_{\mathrm{y}}} \frac{E}{210000}} \sqrt{\frac{k_{\mathrm{E}, \theta}}{k_{0.2, \theta}}} \text { for Class } 4 \text { cross-sections }
\end{gathered}
$$




\section{Design Manual for Structural Stainless Steel method}

The method provided in the Design Manual for Structural Stainless Steel [8] for determination of the flexural buckling resistance uses the same buckling curves as for room temperature, with plateau length $\bar{\lambda}_{0}$ and imperfection factor $\alpha$ as those recommended in Table 6.1 in [8], for elevated temperature design. The design fire buckling resistance $N_{\mathrm{b}, \mathrm{fi}, \mathrm{t}, \mathrm{Rd}}$ is obtained from Eqs (17) and (18), where $A$ is the cross-sectional area of the gross cross-section, $A_{\text {eff }}$ is the cross-sectional area of the effective cross-section, $\chi_{\mathrm{fi}} \mathrm{S}$ as defined in Eq. (19), where $\bar{\lambda}_{\theta}$ is given by Eq. (20). Based on this approach, for all cross-section classes, the flexural buckling resistance of stainless steel columns in fire is determined on the basis of the $0.2 \%$ proof stress $\left(k_{0.2, \theta} f_{\mathrm{y}}\right)$, where $k_{0.2, \theta}$ is the reduction factor for the $0.2 \%$ proof strength and $f_{\mathrm{y}}$ is the design yield strength (taken as the $0.2 \%$ proof stress) at room temperature.

$$
\begin{aligned}
& N_{\mathrm{b}, \mathrm{fi}, \mathrm{t}, \mathrm{Rd}}=\frac{\chi_{\mathrm{fi}} A k_{0.2, \theta} f_{\mathrm{y}}}{\gamma_{\mathrm{M}, \mathrm{fi}}} \text { for Class } 1,2 \text { and } 3 \text { cross-sections } \\
& N_{\mathrm{b}, \mathrm{fi}, \mathrm{t}, \mathrm{Rd}}=\frac{\chi_{\mathrm{fi}} A_{\mathrm{eff}} k_{0.2, \theta} f_{\mathrm{y}}}{\gamma_{\mathrm{M}, \mathrm{fi}}} \text { for Class } 4 \text { cross-sections } \\
& \chi_{f i}=\frac{1}{\varphi_{\theta}+\sqrt{\varphi_{\theta}^{2}-\bar{\lambda}_{\theta}^{2}}} \leq 1.0 \text { with } \varphi=0.5\left[1+\alpha\left(\bar{\lambda}_{\theta}-\bar{\lambda}_{0}\right)+\bar{\lambda}_{\theta}^{2}\right] \\
& \bar{\lambda}_{\theta}=\bar{\lambda}\left(\frac{k_{0.2, \theta}}{k_{\mathrm{E}, \theta}}\right)^{0.5} \text { for all Classes of cross-sections }
\end{aligned}
$$

\section{Analysis of results and discussions}

\subsection{Comparisons with EN 1993-1-2 and Design Manual for Structural Stainless Steel method}

The flexural buckling capacities for the parametric models presented in Section 3 are compared with the predicted capacities determined using the existing fire design methods presented in Section 4 hereafter. In Figure 5(a)-(c), the FE ultimate loads $\left(N_{\mathrm{u}, \theta}\right)$ normalised by the elevated temperature yield loads of the cross-section $\left(A k_{2, \theta} f_{\mathrm{y}}\right)$ versus the elevated temperature member slenderness $\left(\bar{\lambda}_{\theta}\right)$, determined using Eq. (9), for the austenitic, duplex and ferritic hollow section (SHS, RHS and CHS) columns, respectively together with the EN 1993-1-2 [6] flexural buckling curves are presented. For the SHS and RHS columns, the room temperature yield strength $f_{\mathrm{y}}$ is taken as the weighted average $f_{0.2 \text {,wa }}$ value (by area), as described in Eq. (21), in order to normalise out the strength increases in the corner portions associated with cold-work effects during the production of these cross-sections. In Eq. (21), $f_{0.2, \mathrm{f}}$ and $f_{0.2, \mathrm{c}}$ and $A_{\mathrm{f}}$ and $A_{\mathrm{c}}$ are the $0.2 \%$ proof 
stress and the cross-sectional areas for the flat and corner portions of the section, respectively, and $A$ is the total cross-sectional area.

$$
f_{0.2, w a}=\frac{f_{0.2, f} A_{f}+f_{0.2, c} A_{c}}{A}
$$

Figure 6 compares the FE results with the Design Manual for Structural Stainless Steel [8] buckling curves, where for the SHS and RHS columns the plateau lengths are: $\bar{\lambda}_{0}=0.3$ for the austenitic and duplex grades and $\bar{\lambda}_{0}=0.2$ for the ferritic grade and the imperfection parameter $\alpha$ is set to 0.49 for all grades, and for the CHS columns $\bar{\lambda}_{0}$ and $\alpha$ are 0.2 and 0.49 , respectively for all grades. In data presented in Figure 6, the cross-section yield strength was taken as $k_{0.2, \theta} f_{\mathrm{y}}$ and the elevated temperature member slenderness $\bar{\lambda}_{\theta}$ was determined using Eq. (20). Table 7 presents a summary of the numerical comparison results including the mean, minimum, maximum and coefficient of variation (COV) values of the ratios between the ultimate loads obtained from the numerical parametric models $\left(N_{\mathrm{u}, \mathrm{FE}}\right)$ and the predicted capacities $\left(N_{\mathrm{u}, \text { predicted }}\right)$ obtained from EN 1993-1-2 and Design Manual for Structural Stainless Steel methods for $N$ number of numerical data considered.

The EN 1993-1-2 [6] buckling curve which is common for all temperatures generally overpredicts the buckling resistance of the SHS, RHS and CHS columns for the case of austenitic and duplex stainless steels for all modelled temperatures, though it provides a better fit to the ferritic stainless steel columns for temperatures below $800{ }^{\circ} \mathrm{C}$. This is expected as this curve was originally calibrated against carbon steel column data and inaccuracies are observed when its predicted capacities are compared with the FE obtained capacities for stainless steel columns, especially the austenitic and duplex grades which possess comparatively different stress-strain responses at elevated temperatures to those of carbon steel. The Design Manual for Structural Stainless Steel provisions [8], which use the elevated temperature $0.2 \%$ proof stress rather than the elevated temperature stress at 2\% total strain used in EN 1993-1-2, significantly under-predicts the resistance of the stockier columns with low elevated temperature member slenderness values as it limits the cross-section predicted resistance to the squash load based on the $0.2 \%$ proof stress, though it gives improved predictions than the EN 1993-1-2 method for higher slenderness ranges. Similar observations were made by Ng and Gardner [24] and Uppfeldt et al. [25] in their studies of elevated temperature resistance of stainless steel cold-formed SHS and RHS columns. Note that no comparisons have been made with the method proposed by Lopes et al. [20] as it was developed for welded I-section columns, with distinctly different buckling performance compared with cold-formed box sections columns. 


\subsection{Extension of Lopes et al. method for SHS, RHS and CHS cold-formed columns}

Buckling curves of the same form as the Lopes at al. [20] formulation as presented in Section 4.2 were calibrated on the basis of the normalised FE data for the SHS, RHS and CHS cold-formed stainless steel columns generated herein to extend its application to these sections. The Lopes et al. method uses the $2 \%$ strength $\left(k_{2, \theta} f_{\mathrm{y}}\right)$ in its buckling curve formulation and in that respect allows harmonisation between the design rules provided for carbon steel and stainless steel. The use of the $\alpha$ parameter, as given by Eqs (15) and (16), which is a function of elevated temperature strength and stiffness reduction factors, enables different buckling curves for different temperatures, which is required for stainless steel columns as the FE data presented in Figure 5 confirm. In addition, the introduction of the $\beta$ parameter in the $\chi_{\mathrm{fi}}$ equation, which is similar to that employed in the lateral torsional buckling formulation in Clause 6.3.2.3 of EN 1993-1-1 [23], allows the shape of the buckling curve to better represent the normalised FE data.

The $\beta$ and $\eta$ parameters, which were fitted against data on welded I-section columns in [20], were calibrated against the FE data for austenitic, duplex and ferritic SHS, RHS and CHS stainless steel columns generated in Section 3, and their proposed values are presented in Table 8. Figures 7 and 8 show the FE ultimate loads normalised by the cross-section elevated temperature yield loads $\left(A k_{2, \theta} f_{\mathrm{y}}\right)$, plotted against the elevated temperature member slenderness $\bar{\lambda}_{\theta}$ from Eq. (9), together with the new calibrated buckling curves for temperature bounds $200{ }^{\circ} \mathrm{C}$ and $800{ }^{\circ} \mathrm{C}$ for SHS/RHS and CHS columns respectively, also depicted.

Comparisons between the FE results and the predicted resistances using the new calibrated $\beta$ and $\eta$ parameters presented in Table 8 were carried out and the numerical comparisons in terms of $N_{\mathrm{u}, \mathrm{FE}} / N_{\mathrm{u} \text {,predicted }}$ ratios are reported in Table 7 and also presented in Figure 9 . From the presented comparison results, it is shown that the new calibrated buckling curves provide an improved representation of the buckling resistance of cold-formed stainless steel SHS, RHS and CHS columns in fire and allow their flexural buckling capacity at elevated temperature to be predicted with higher degree of accuracy as well as with significantly less scatter.

\section{Reliability analysis}

Safety assessments according to the method recommended by Kruppa [26] for development of fire design rules were conducted to assess the reliability and accuracy of the existing and the new calibrated design methods for predicting the flexural buckling resistance of cold-formed austenitic, duplex and ferritic SHS/RHS and CHS stainless steel columns in fire. The method by Kruppa [26] sets out three distinct reliability criteria to compare the theoretical resistance $r_{\mathrm{ti}}$ 
values, determined form the considered design method, with the experimental (or numerical) values $r_{\mathrm{ei}}$, for each specimen as listed hereafter and further illustrated in Figure 10.

- Criterion 1: The percentage of the theoretical resistance values $r_{\mathrm{ti}}$ on the unsafe side by more than $15 \%$ of the experimental (or numerical) values $r_{\mathrm{ei}}$ i.e. $r_{\mathrm{ti}}>1.15 r_{\mathrm{ei}}$, which should be zero.

- Criterion 2: The percentage of the theoretical resistance values $r_{\mathrm{ti}}$ on the unsafe side i.e. $r_{\mathrm{ti}}>$ $1.0 r_{\mathrm{ei}}$, which should be less than $20 \%$.

- Criterion 3: The mean value of all percentage difference between the theoretical resistance values $r_{\mathrm{ti}}$ and the experimental (or numerical) values $r_{\mathrm{ei}}$ which should be on the safe side and less than zero.

Table 9 provides a summary of the safety assessment results for the predicted resistances from the considered design methods, where it is shown that unlike to the EN 1993-1-2 [6] and the Design Manual for Structural Stainless Steel [8] methods, the three reliability criteria are satisfied by the new calibrated buckling curves.

\section{Worked Example}

An example is provided in this section to demonstrate the workings of the proposed method. The minor axis buckling resistance $N_{\mathrm{b}, \mathrm{z}, \mathrm{fi}, \mathrm{t}, \mathrm{Rd}}$ of a stainless steel RHS $100 \times 50 \times 6$ column with a limiting design temperature of $600{ }^{\circ} \mathrm{C}$ is determined. The column length is $2.7 \mathrm{~m}$ and has pinned support conditions. The cross-section classification is Class 1 according to [8]. The material properties used throughout this worked example are taken from the Design Manual for Stainless Steel Structures [8]. All symbols in accordance with Eurocode 3 notation and are as previously defined.

\section{Cross-section geometric and material properties}

Material properties - Austenitic grade EN 1.4301

$f_{\mathrm{y}}=230 \mathrm{~N} / \mathrm{mm}^{2}, f_{\mathrm{u}}=540 \mathrm{~N} / \mathrm{mm}^{2}, E=200000 \mathrm{~N} / \mathrm{mm}^{2}, k_{2, \theta}=0.68$ and $k_{\mathrm{E}, \theta}=0.76\left(\right.$ at $\left.600{ }^{\circ} \mathrm{C}\right)$

Geometric properties - RHS $100 \times 50 \times 6$

$h=100 \mathrm{~mm}, b=50 \mathrm{~mm}, t=6 \mathrm{~mm}, r_{\mathrm{i}}=12 \mathrm{~mm}, A=1500 \mathrm{~mm}^{2}, I_{\mathrm{zz}}=547239 \mathrm{~mm}^{4}$

\section{Determine the non-dimensional slenderness}

$\bar{\lambda}_{z}=\sqrt{\frac{A f_{\mathrm{y}}}{N_{\mathrm{cr}, \mathrm{z}}}}=\sqrt{\frac{1500 \times 230}{\pi^{2} \times 200000 \times 547239 / 2700^{2}}}=1.53$

(the column effective length $L_{\mathrm{cr}}$ is taken as $1 \times$ column length $=2.7 \mathrm{~m}$ ) 
$\bar{\lambda}_{\mathrm{z}, \theta}=\bar{\lambda}\left(\frac{k_{2, \theta}}{k_{\mathrm{E}, \theta}}\right)^{0.5}=1.53\left(\frac{0.68}{0.76}\right)^{0.5}=1.44$

\section{Determine the buckling reduction factor}

$$
\begin{aligned}
& \alpha=\eta \sqrt{\frac{235}{f_{\mathrm{y}}} \times \frac{E}{210000}} \sqrt{\frac{k_{\mathrm{E}, \theta}}{k_{2, \theta}}}=1.5 \sqrt{\frac{235}{230} \times \frac{200000}{210000}} \sqrt{\frac{0.76}{0.68}}=1.56 \\
& \varphi=0.5\left[1+\alpha \bar{\lambda}_{\theta}+\beta \bar{\lambda}_{\theta}^{2}\right]=0.5\left[1+1.56 \times 1.44+0.8 \times 1.44^{2}\right]=2.46 \\
& (\eta=1.5 \text { and } \beta=0.8 \text { for Austenitic SHS/RHS columns }- \text { from Table } 8)
\end{aligned}
$$

$$
\chi_{\mathrm{fi}}=\frac{1}{\varphi_{\theta}+\sqrt{\varphi_{\theta}^{2}-\beta \bar{\lambda}_{\theta}^{2}}}=\frac{1}{2.46+\sqrt{2.46^{2}-0.8 \times 1.44^{2}}}=0.22
$$

\section{Determine the member buckling resistance in compression}

$$
N_{\mathrm{b}, \mathrm{z}, \mathrm{fi}, \mathrm{t}, \mathrm{Rd}}=\frac{\chi_{\mathrm{fi}} A k_{2, \theta} f_{\mathrm{y}}}{\gamma_{\mathrm{M}, \mathrm{fi}}}=\frac{0.22 \times 1500 \times 0.68 \times 230}{1.0}=51.6 \mathrm{kN}
$$

\section{Conclusions}

The flexural buckling response of stainless steel columns of square, rectangular and circular hollow sections in fire was assessed through a numerical modelling investigation. The developed FE models were initially validated against the room and elevated temperatures column tests reported in the literature and then adopted to conduct a systematic parametric study. The FE generated flexural buckling data were used to carry out an assessment of the design methods provided in EN 1993-1-2 [6] and the Design Manual for Stainless Steel Structures [8] where it was shown that inaccurate and unsafe flexural buckling resistances in fire are predicted by both methods. New buckling curves for cold-formed stainless steel square, rectangular and circular hollow section columns in fire in line with the Lopes et al.'s [20] method were proposed on the basis of the FE results, which were shown to consistently predict the flexural buckling capacities of the columns in fire with higher degree of accuracy as well as with significantly less scatter. Moreover, the predicted resistances from the proposed buckling curves were assessed in accordance with the three reliability criteria set out by Kruppa [26], and were shown to consistently satisfy the specified safety levels required. 


\section{References}

[1] N. Tondini, B. Rossi, J.M. Franssen. Experimental investigation on ferritic stainless steel columns in fire. Fire Safety Journal, 62 (2013), pp. 238-248.

[2] Y. Huang, B. Young. Structural performance of cold-formed lean duplex stainless steel beams at elevated temperatures. Thin-Walled Structures, 129 (2018), pp. 20-27.

[3] A. Pournaghshband, S. Afshan, A. Foster. Structural fire performance of axially and rotationally restrained stainless steel columns. Thin-Walled Structures, 137 (2019), pp. 561-572.

[4] Y. Huang, B. Young. Stress-strain relationship of cold-formed lean duplex stainless steel at elevated temperatures. Journal of Constructional Steel Research, 92 (2014), pp. 103-113.

[5] J. Chen, B. Young. Stress-strain curves for stainless steel at elevated temperatures. Engineering Structures, 28 (2) (2006), pp. 229-239.

[6] EN 1993-1-2 Eurocode 3: Design of Steel Structures - Part 1-2: General rules - Structural fire design. European Committee for Standardization, Brussels (2005).

[7] EN 1993-1-4 Eurocode 3: Design of Steel Structures - Part 1-4: General Rules Supplementary Rules for Stainless Steels. European Committee for Standardization, Brussels (2015).

[8] Stainless Steel Design Manual (fourth edition), Steel Construction Institute (SCI) (2017).

[9] ABAQUS. Version 2016, Dassault Systmes Simulia Corp. USA 2016.

[10] T. Ala-Outinen, T. Oksanen. Stainless steel compression members exposed to fire. VTT research notes 1864. Espoo (Finland) (1997).

[11] N.R. Baddoo, L. Gardner. Member behaviour at elevated temperatures. ECSC project Development of the use of stainless steel in construction, Contract No. 7210 SA/842. The Steel Construction Institute, UK, WP5.2. (2000).

[12] O. Zhao, L. Gardner, B. Young B. Testing and numerical modelling of austenitic stainless steel CHS beam-columns. Engineering Structures, 111 (2016), pp. 263-274.

[13] C. Buchanan, E. Real, L. Gardner. Testing, simulation and design of cold-formed stainless steel CHS columns. Thin-Walled Structures, 130 (2018), pp. 297-312.

[14] M. Theofanous, L. Gardner. Testing and numerical modelling of lean duplex stainless steel hollow section columns. Engineering Structures, 31 (12) (2009), pp. 3047-3058. 
[15] L. Gardner . Elevated temperature material properties of stainless steel alloys. Journal of Constructional Steel Research, 66 (5) (2010), pp. 634-647.

[16] R.B. Cruise, L. Gardner. Strength enhancements induced during cold forming of stainless steel sections. Journal of Constructional Steel Research, 64 (11) (2008), pp. 1310-1316.

[17] S. Afshan, O. Zhao, L. Gardner. Standardised material properties for numerical parametric studies of stainless steel structures and buckling curves for tubular columns. Journal of Constructional Steel Research, 152 (2019), pp. 2-11.

[18] L. Gardner, D.A. Nethercot. Numerical modelling of stainless steel structural components a consistent approach. Journal of Structural Engineering (ASCE), 130 (10) (2004), pp. 15861061.

[19] EN 1363-1: Fire resistance tests - Part 1: General requirements. European Committee for standardization, Brussels (1999).

[20] N. Lopes, P. Vila Real, L. da Silva, J.M. Franssen. Axially Loaded Stainless Steel Columns in Case of Fire. Journal of Structural Fire Engineering, 1 (1) (2010), pp. 43-60.

[21] EN 1090-2: Execution of steel structures and aluminium structures - Part 2: Technical requirements for steel structures. European Committee for Standardization. Brussels (2008).

[22] EN 1993-1-5 Eurocode 3: Design of steel structures - Part 1-5: Plated structural elements. European Committee for Standardization, Brussels (2006).

[23] EN 1993-1-1 Eurocode 3: Design of steel structures - Part 1-1: General rules and rules for buildings. European Committee for Standardization, Brussels (2005).

[24] K.T. Ng, L. Gardner. Buckling of stainless steel columns and beams in fire. Engineering Structures. 29 (5) (2007), pp. 717-730.

[25] B. Uppfeldt, T. Ala Outinen, M. Veljkovic. A design model for stainless steel box columns in fire. Journal of Constructional Steel Research. 64, (2008), pp. 1294-1301

[26] J. Kruppa. Eurocodes Fire parts: Proposal for a methodology to check the accuracy of assessment methods. CEN TC 250, Horizontal Group Fire, Document no: 99/130, (1999). 


\section{Figures}

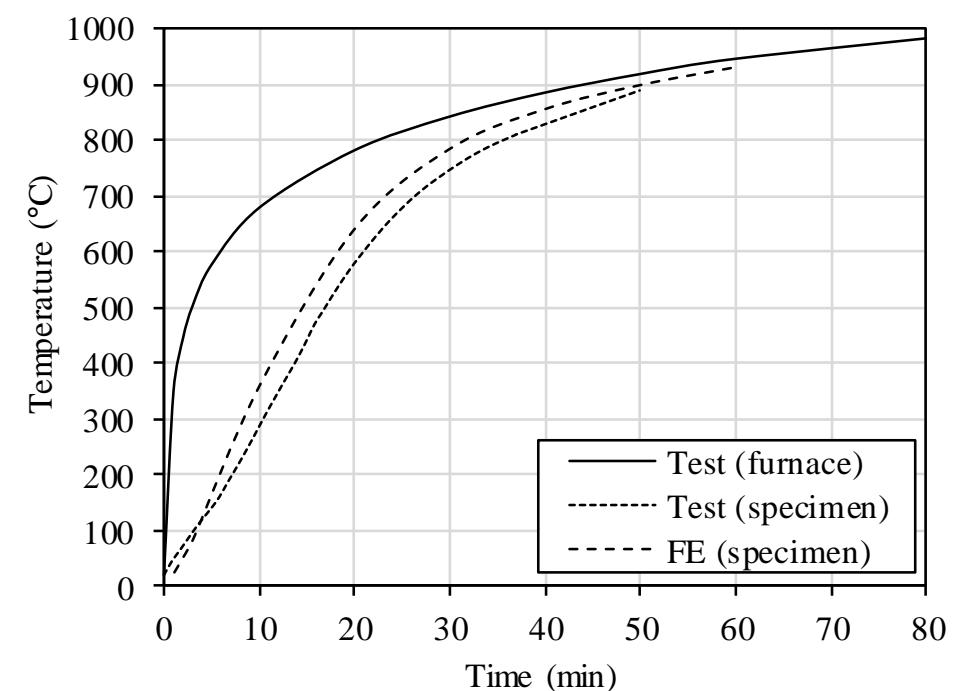

Figure 1: Comparison of test and FE temperature development for RHS $150 \times 75 \times 6$.

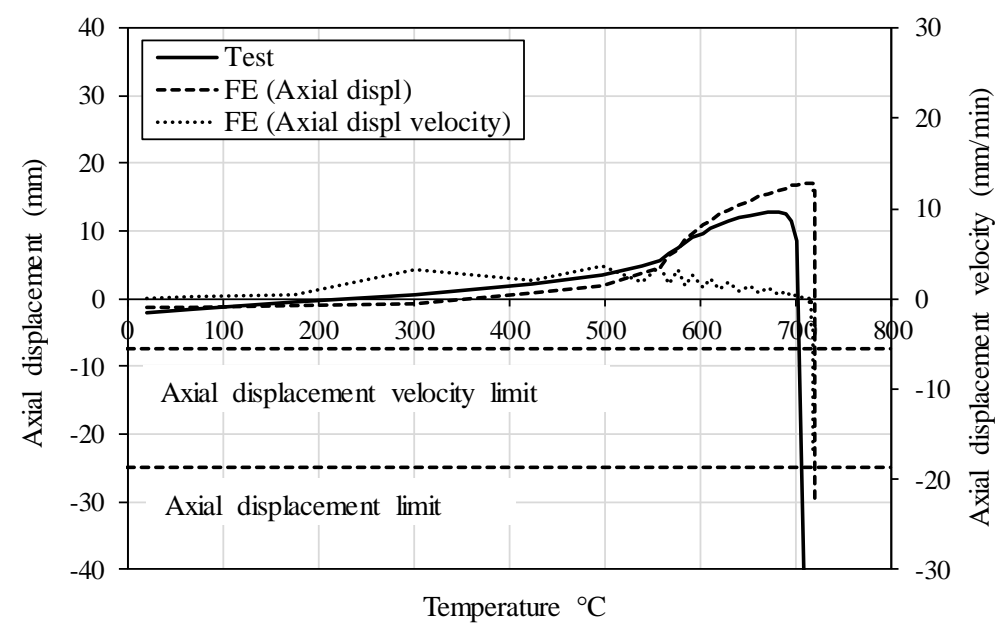

(a) SHS $80 \times 80 \times 3-2500$ column tested in [1].

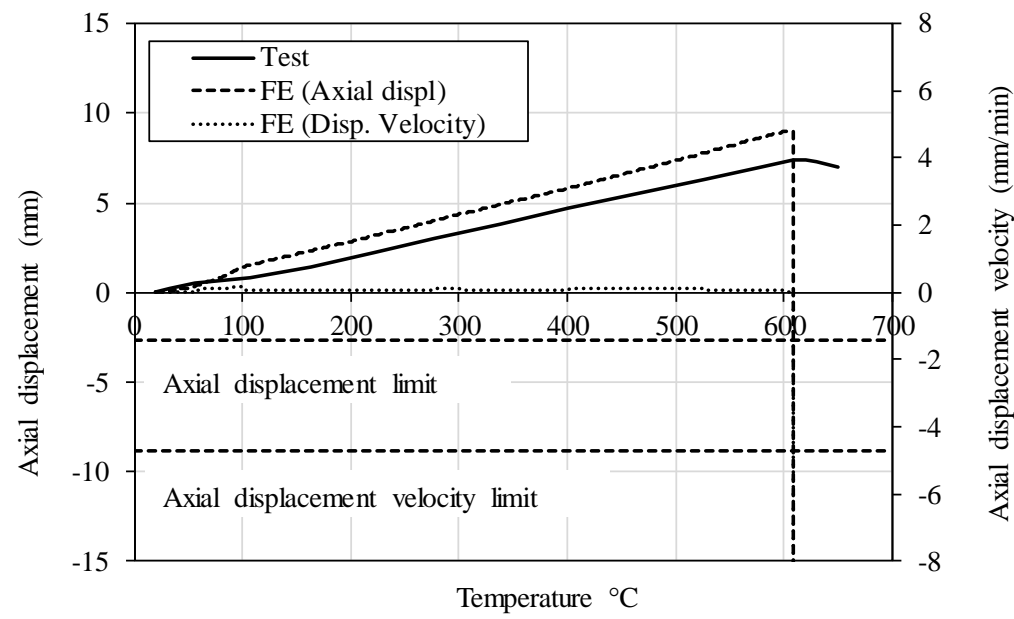

(b) RHS $40 \times 40 \times 4-\mathrm{T} 3$ tested in [10]. 


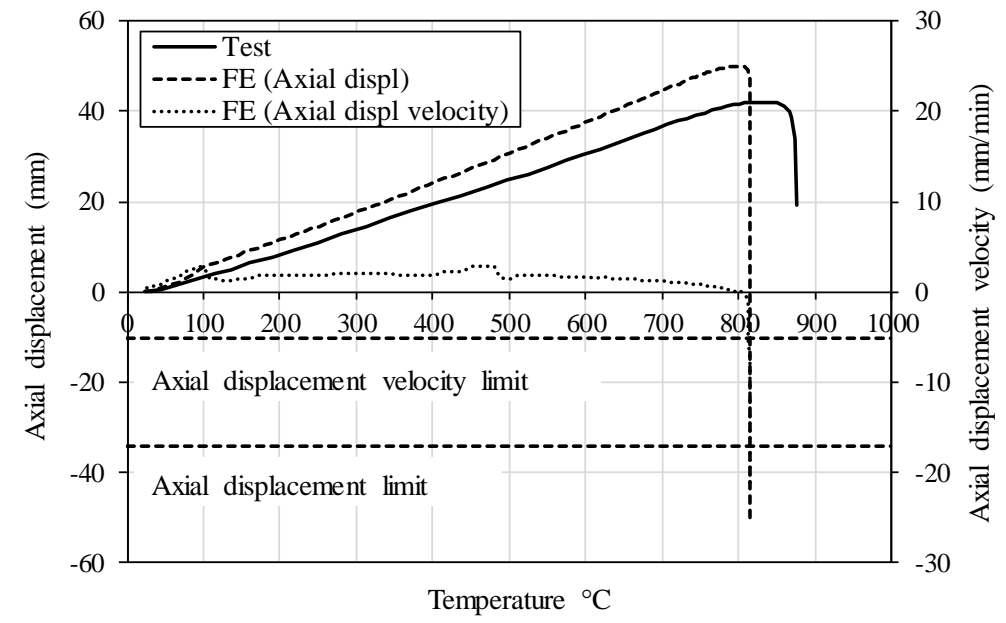

(c) RHS $150 \times 75 \times 6$ tested in [11].

Figure 2: Experimental and numerical axial displacement-temperature responses for (a) SHS $80 \times 80 \times 3-2500$, (b) RHS $40 \times 40 \times 4-$ T3 and (c) RHS $150 \times 75 \times 6$ columns.

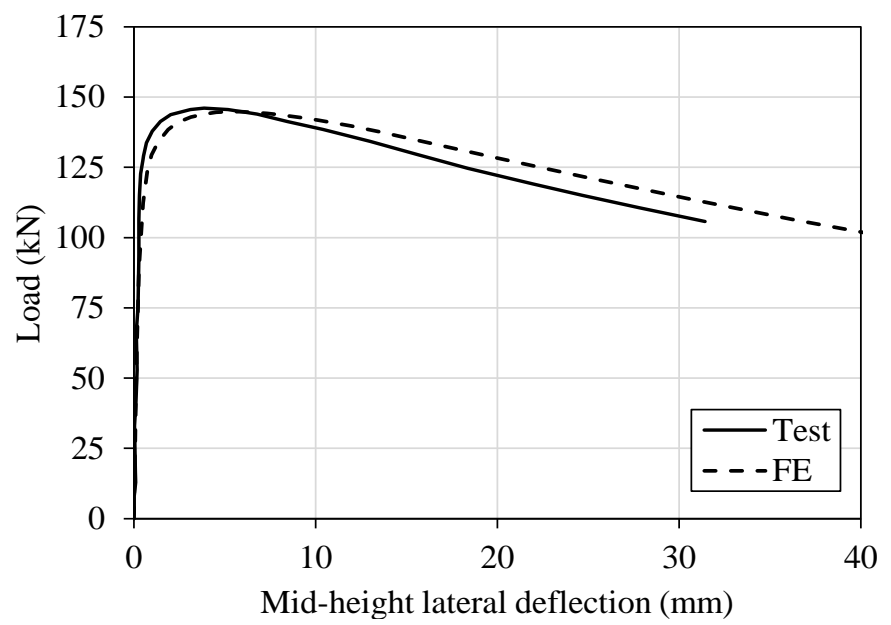

(a) CHS $76.3 \times 3$ column tested in [12].

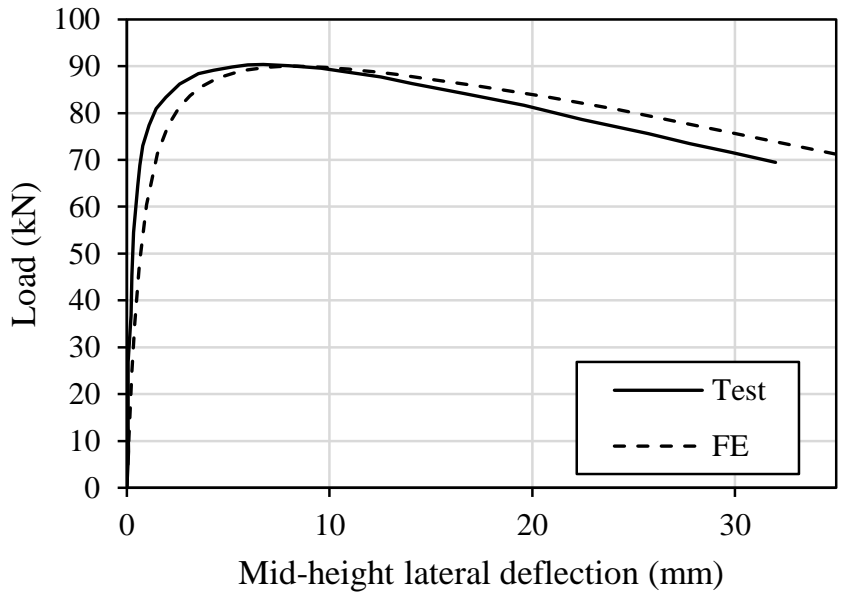

(b) CHS $60.5 \times 2.8$ column tested in [12] 


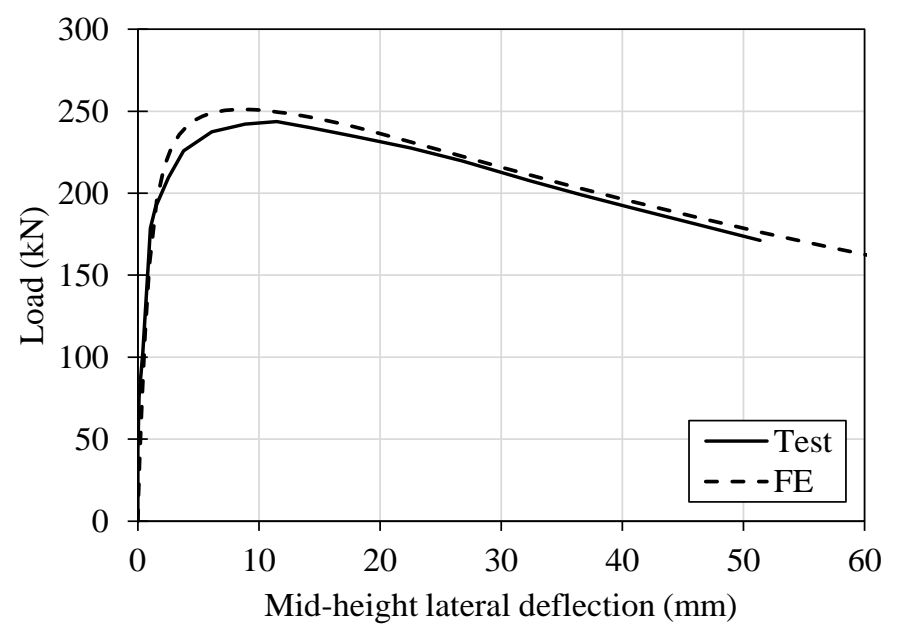

(c) CHS 88.9×2.6-1650 column tested in [13].

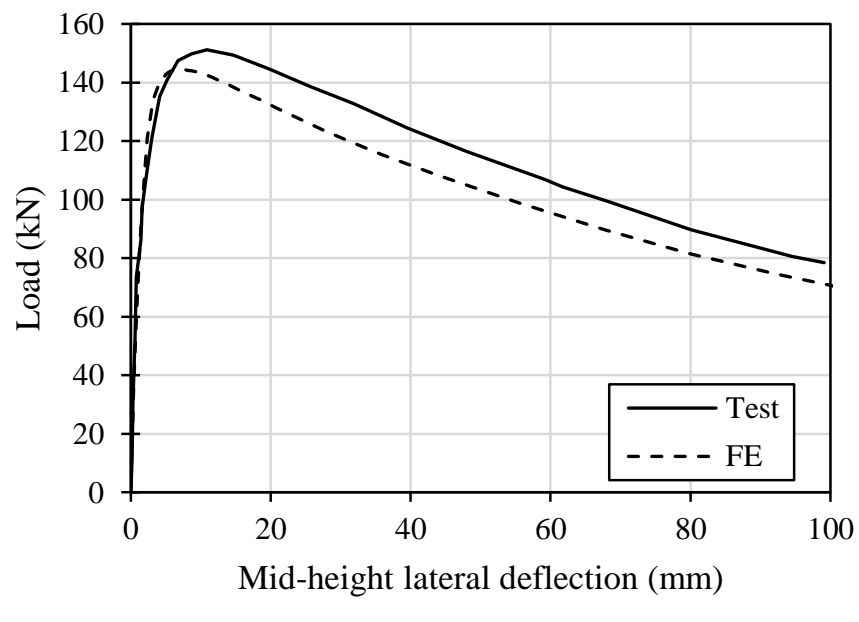

(d) CHS 106 $\times 3-3080$ column tested in [13]

Figure 3: Experimental and numerical load-mid-height lateral deflection responses for (a) CHS 76.3×3, (b) CHS 60.5×2.8, (c) CHS 88.9×2.6-1650 and (d) CHS 106×3-3080 columns. 

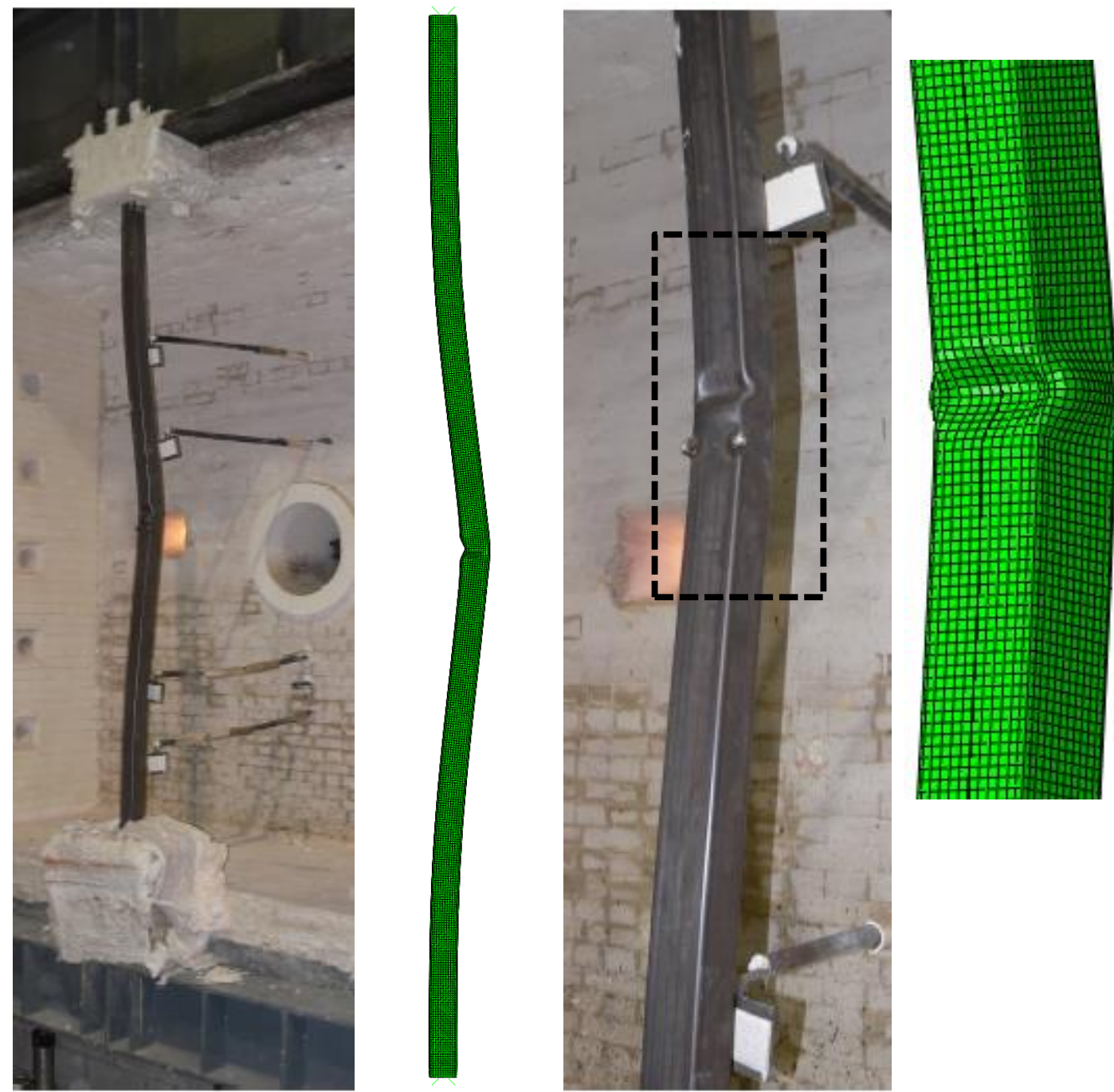

Figure 4: Test and FE failure modes for SHS $80 \times 80 \times 3-3000$ column tested in [1]. 


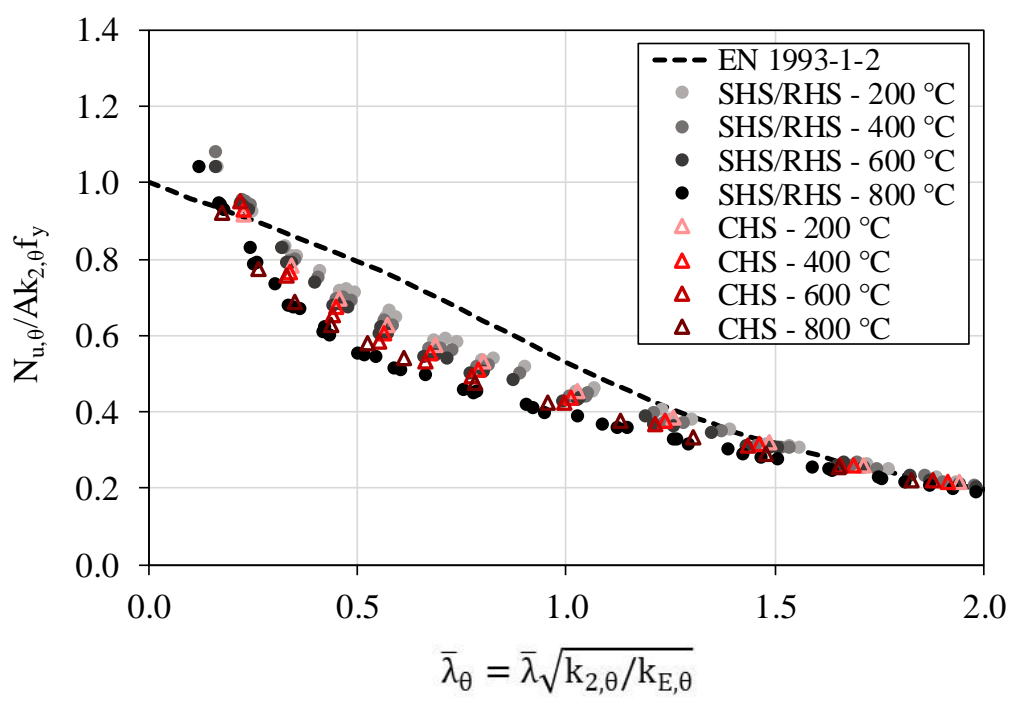

(a) Austenitic

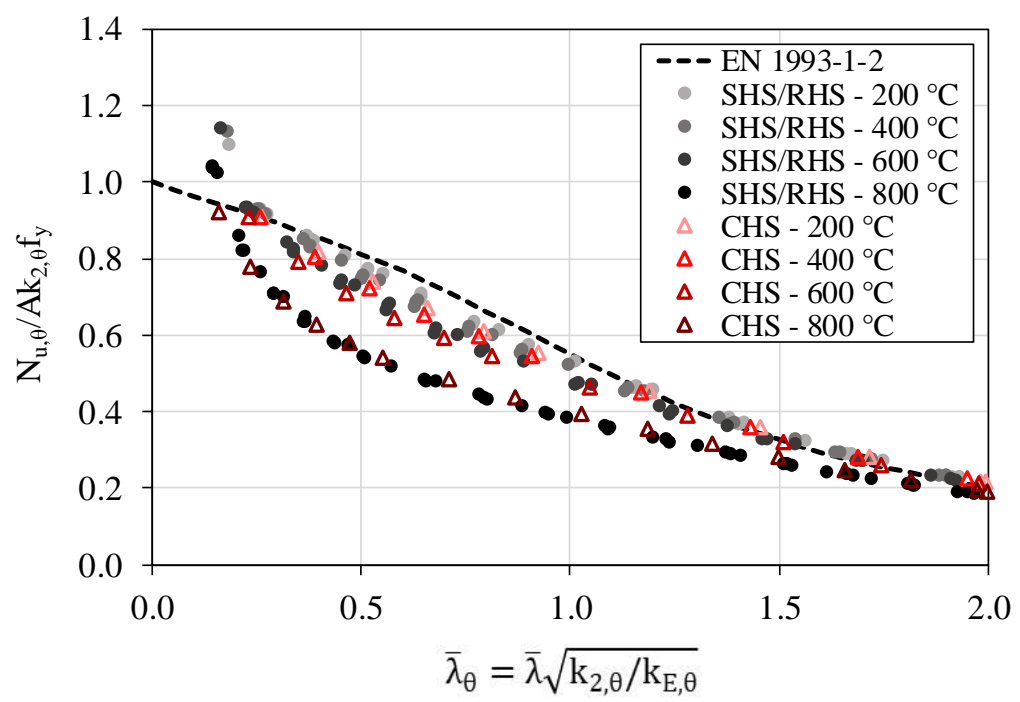

(b) Duplex

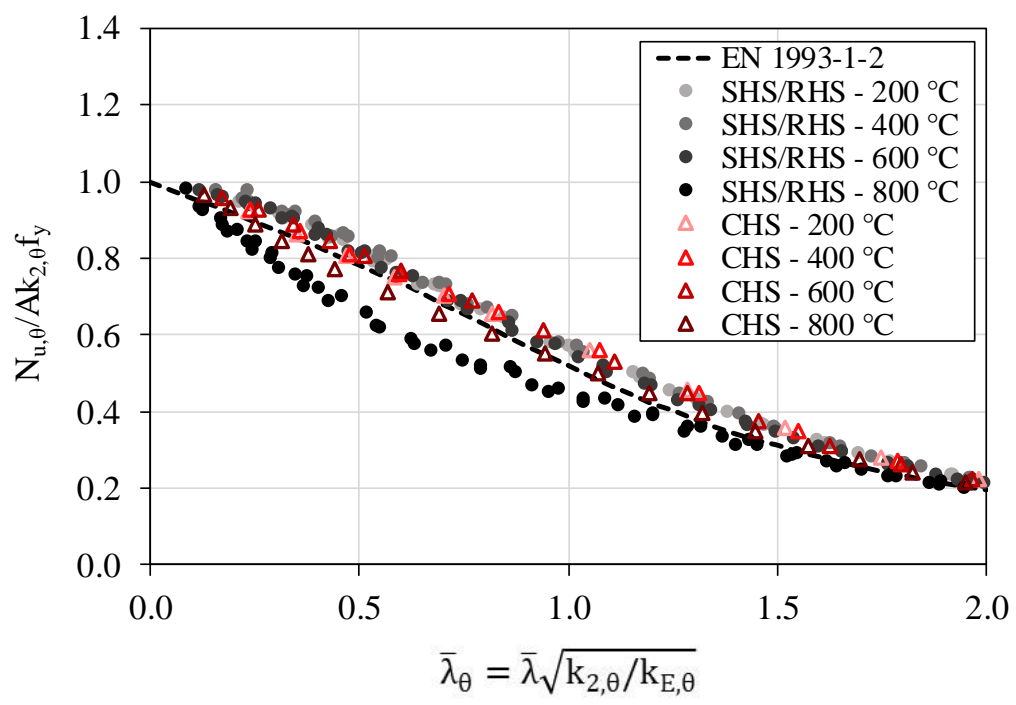

(c) Ferritic

Figure 5: Comparison of FE results with the EN 1993-1-2 [6] buckling curve for (a) austenitic, (b) duplex and (c) ferritic SHS, RHS and CHS columns. 


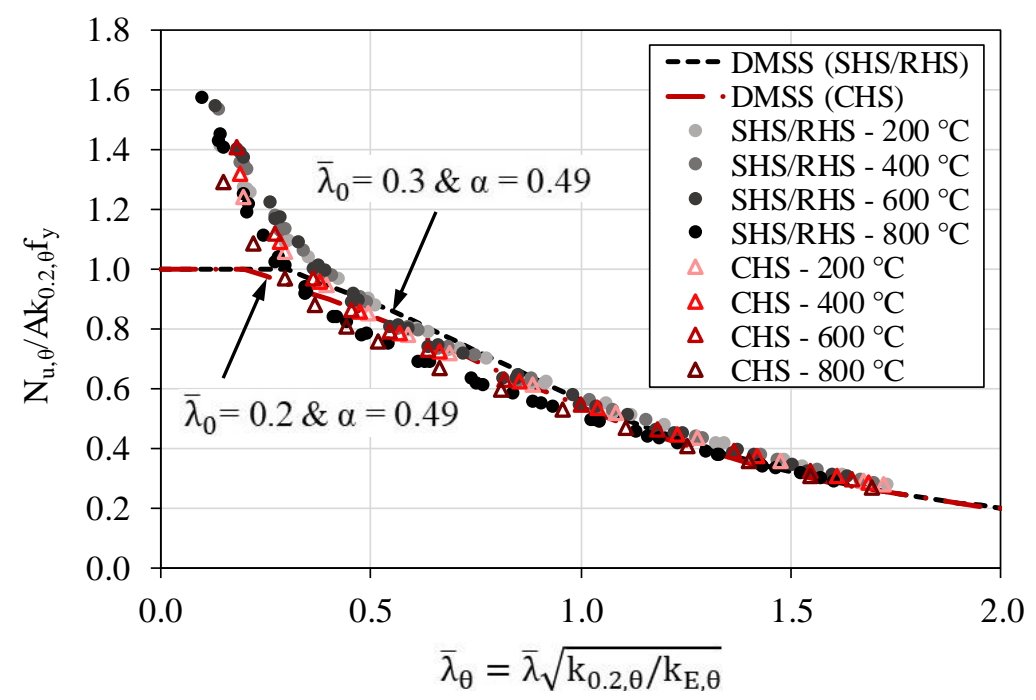

(a) Austenitic

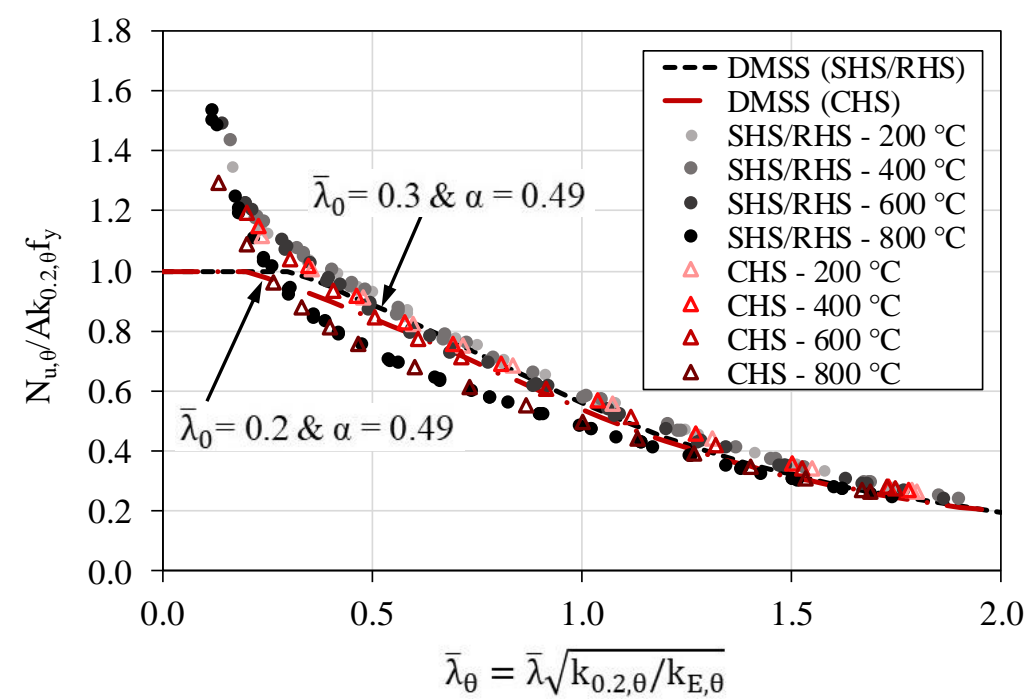

(b) Duplex

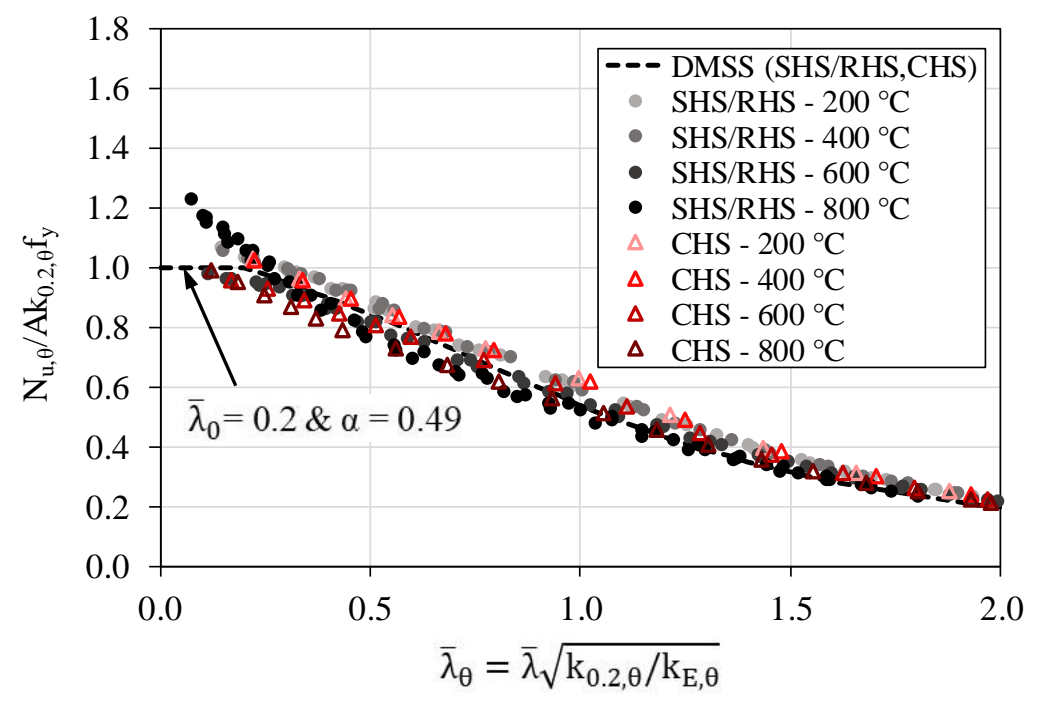

(c) Ferritic

Figure 6: Comparison of FE results with the Design Manual for Structural Stainless Steel (DMSS) [8] buckling curves for (a) austenitic, (b) duplex and (c) ferritic SHS, RHS and CHS columns. 


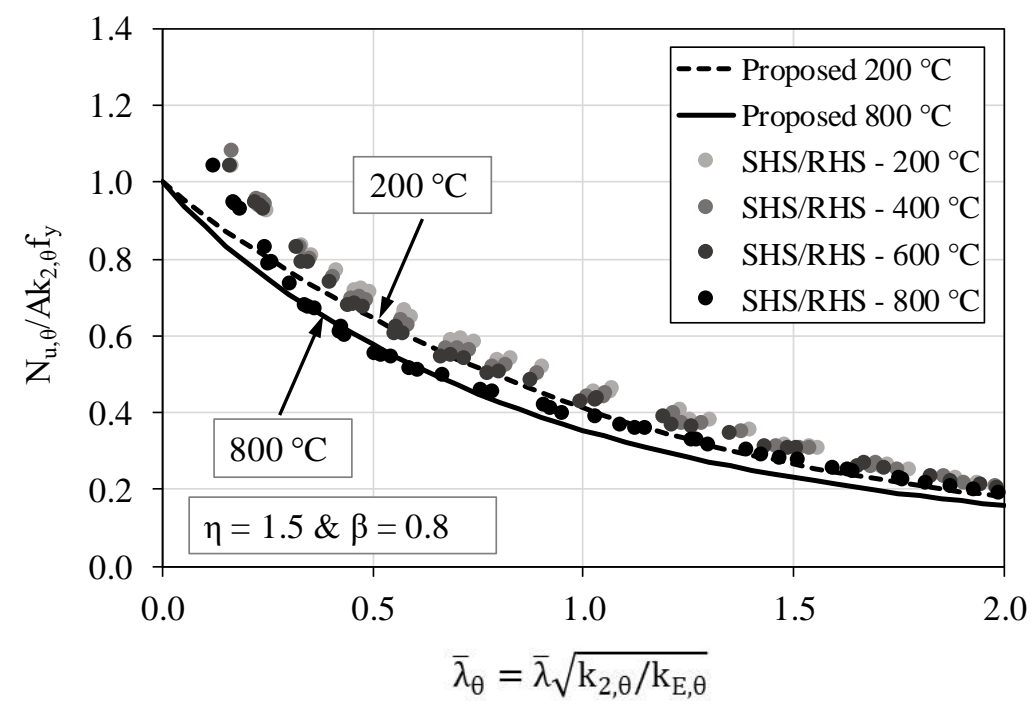

(a) Austenitic

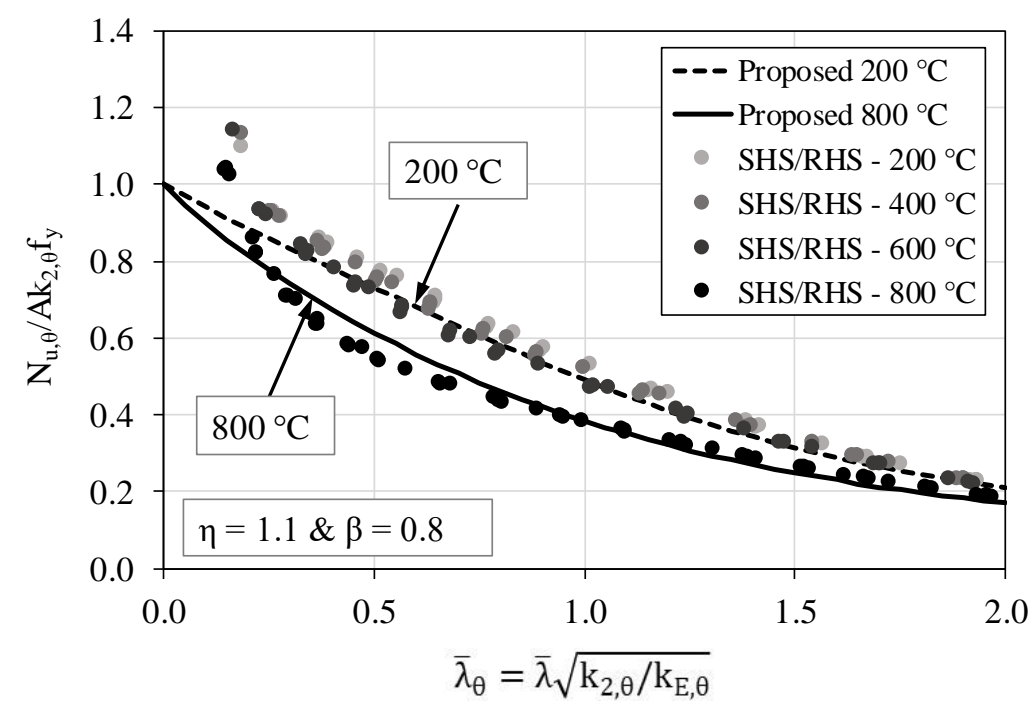

(b) Duplex

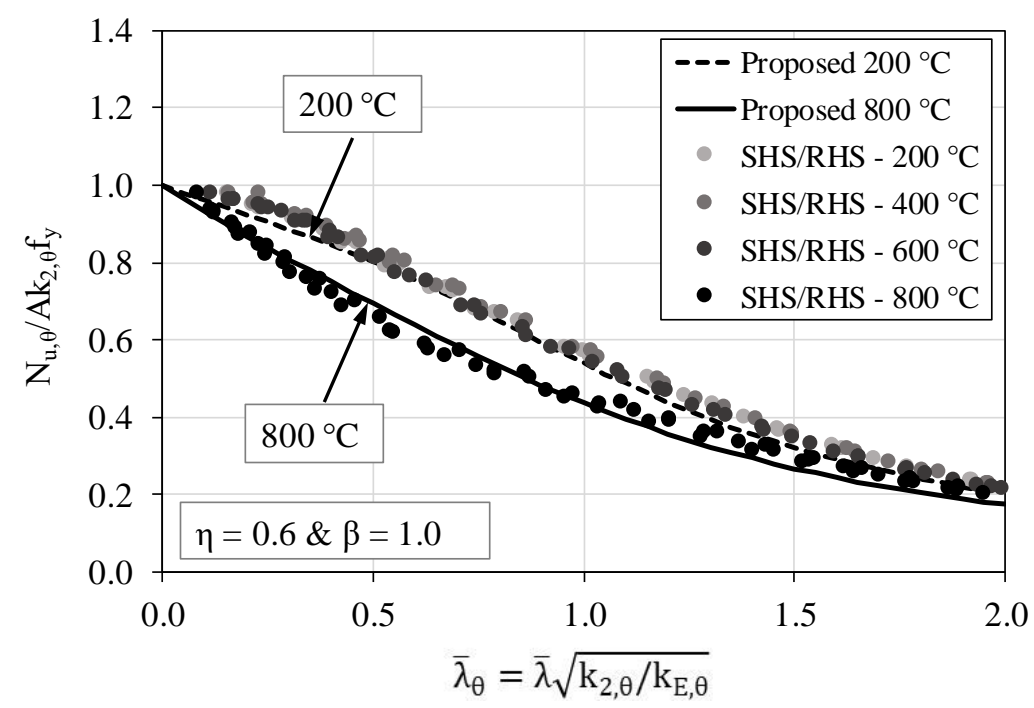

(c) Ferritic

Figure 7: Comparison of FE results with the proposed buckling curves for (a) austenitic, (b) duplex and (c) ferritic SHS and RHS columns. 


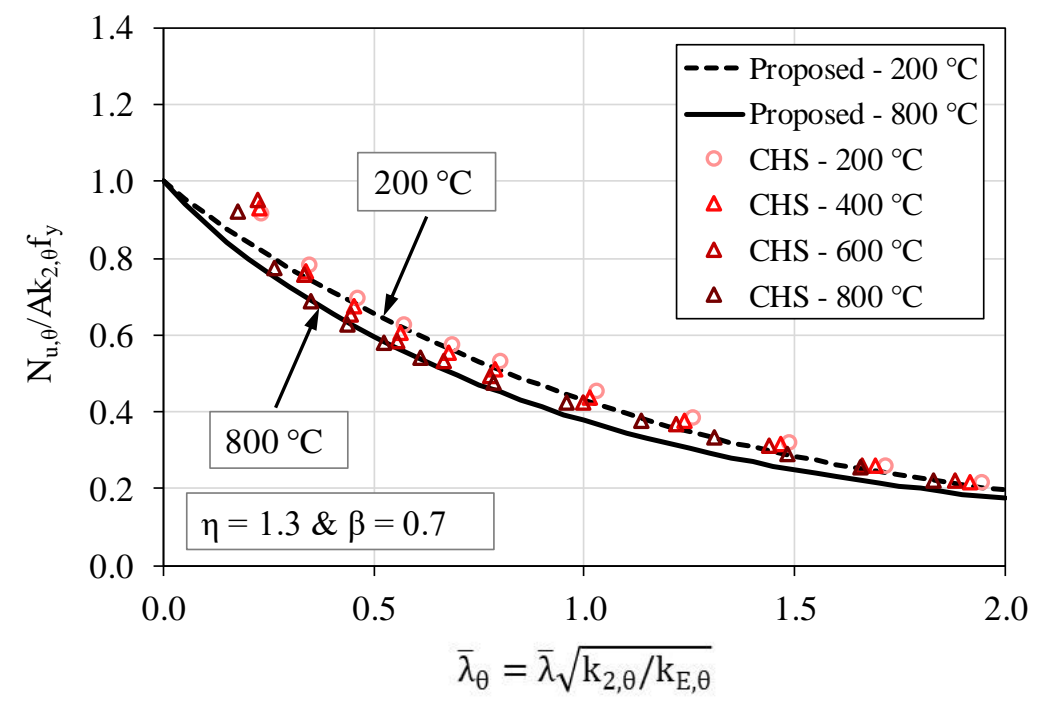

(a) Austenitic

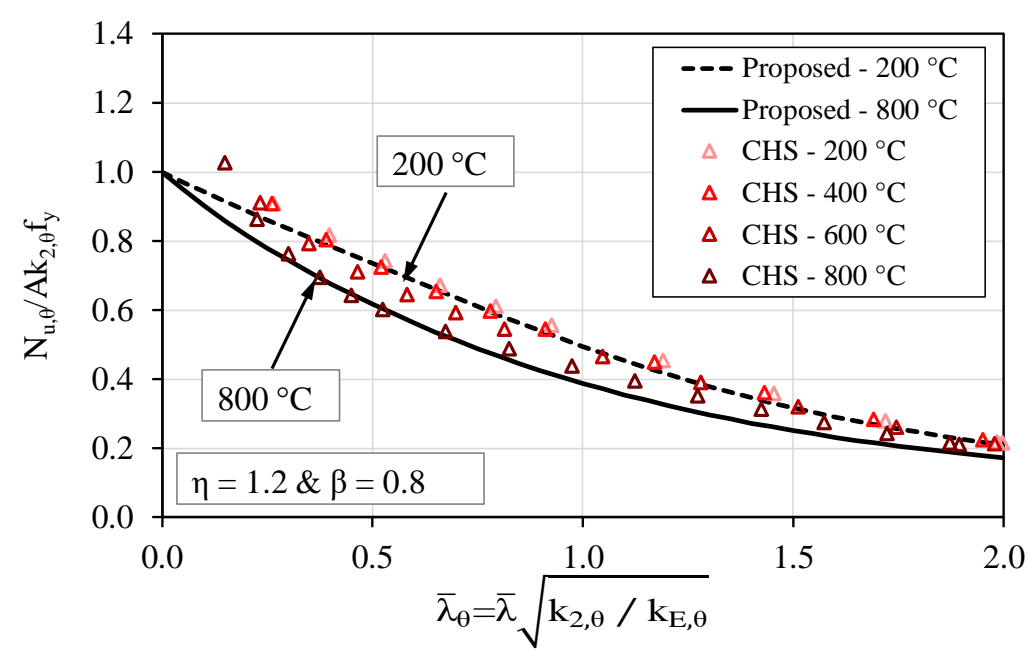

(b) Duplex

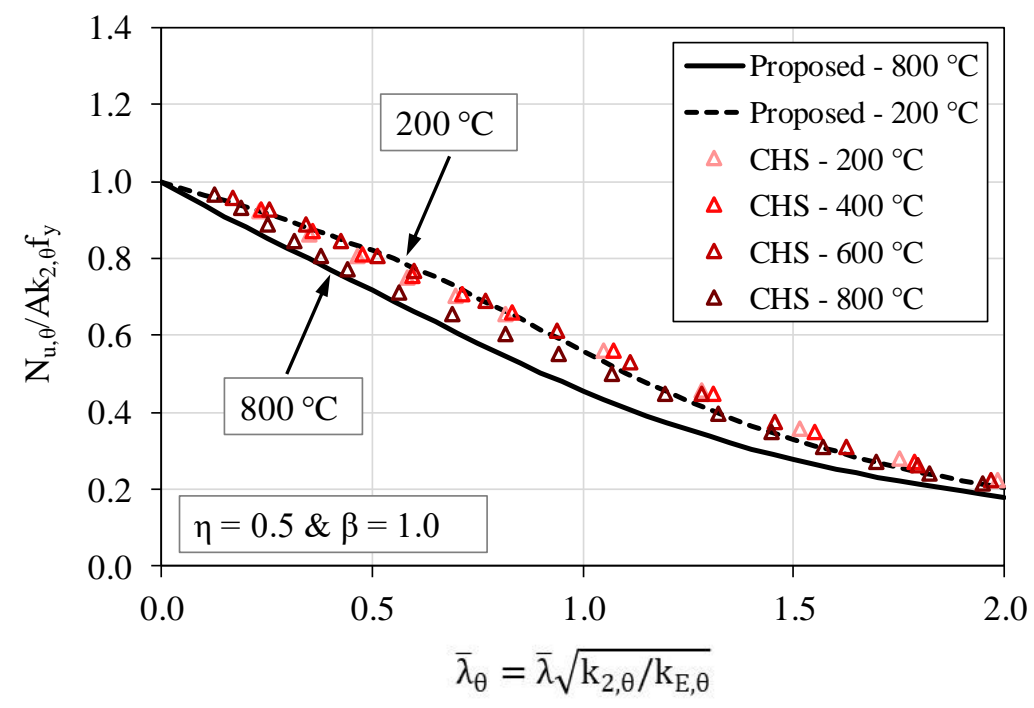

(c) Ferritic

Figure 8: Comparison of FE results with the proposed buckling curves for (a) austenitic, (b) duplex and (c) ferritic CHS columns. 


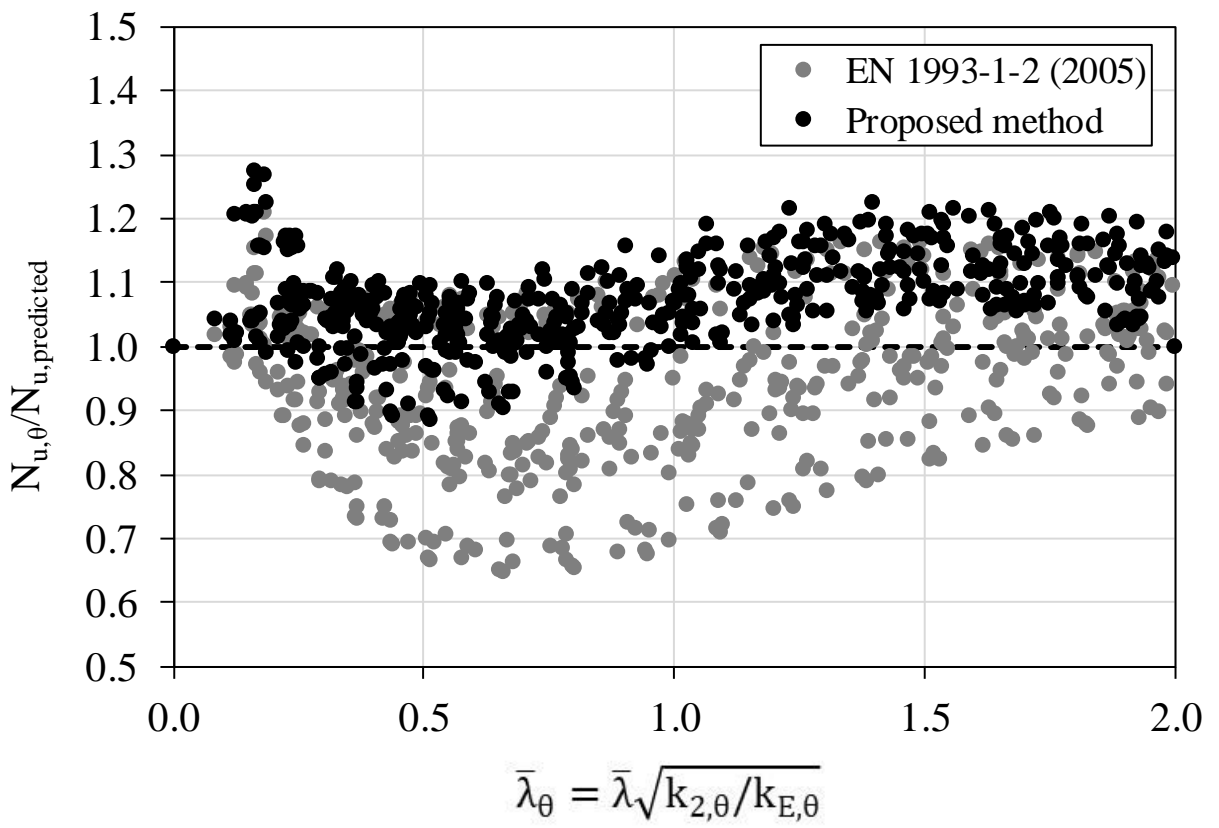

(a) SHS/RHS

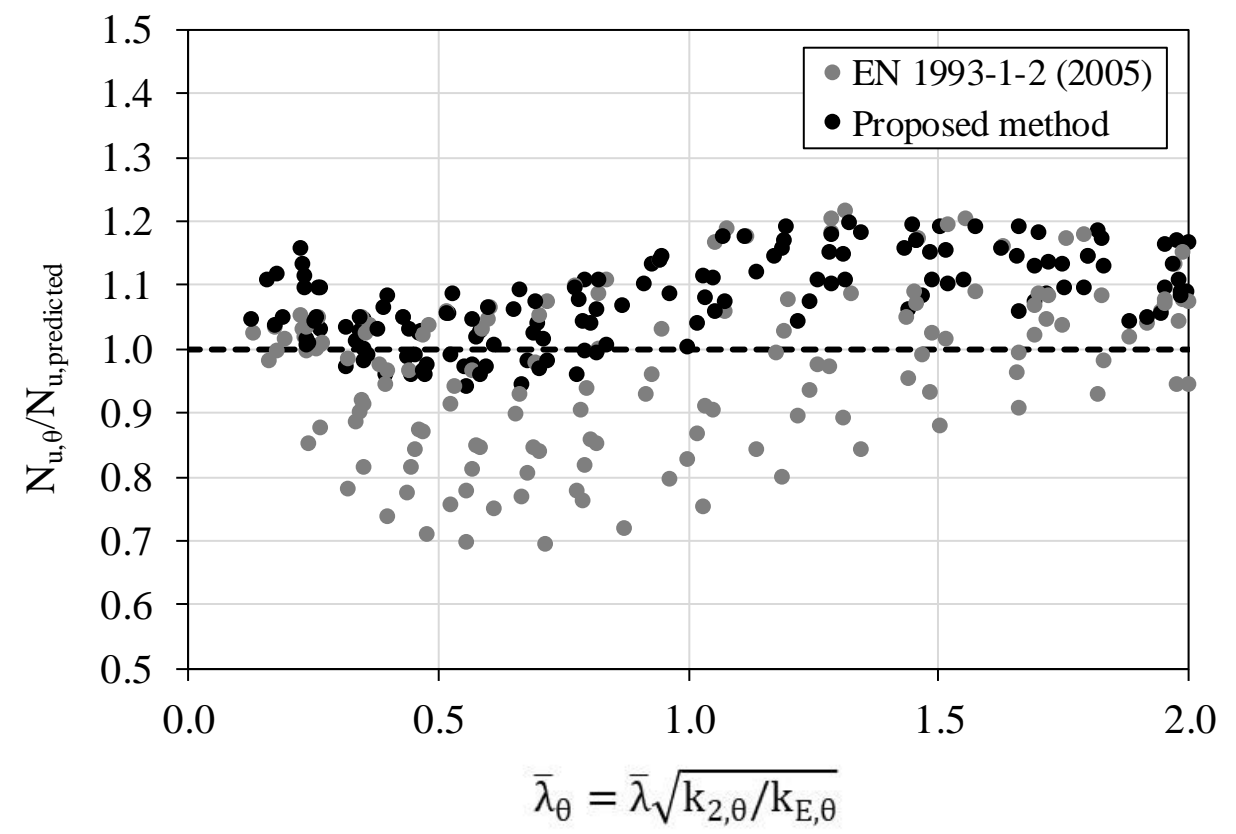

(b) CHS

Figure 9: Comparisons of predicted capacities from EN 1993-1-2 and proposed methods for stainless steel (a) SHS/RHS and (b) CHS columns. 


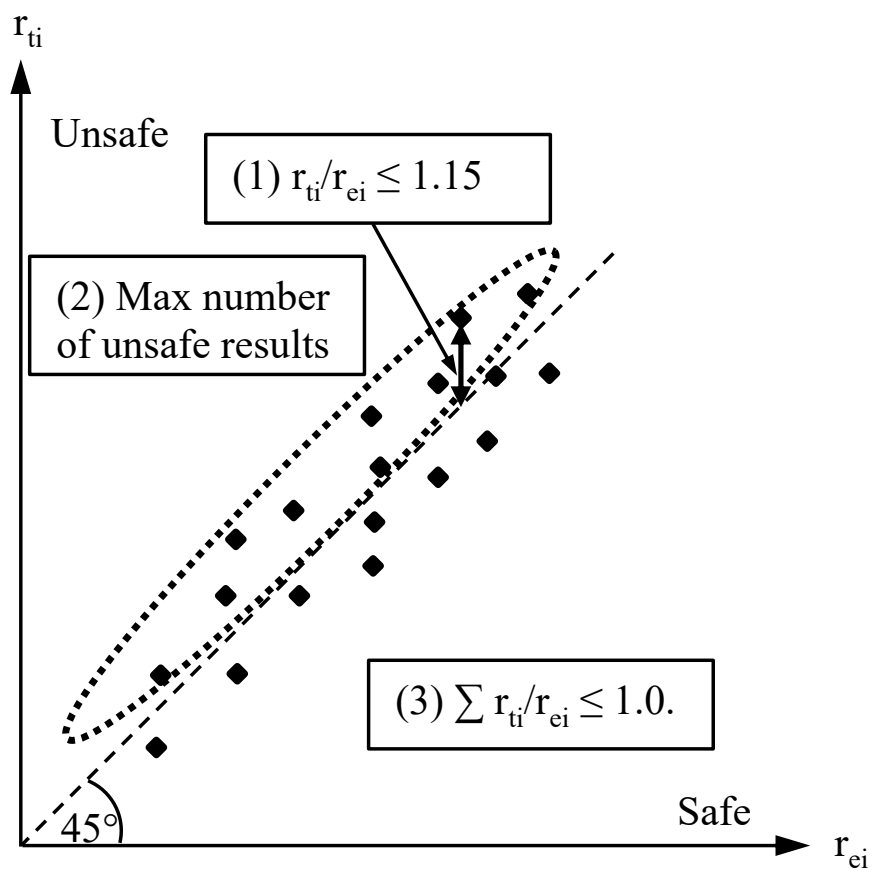

Figure 10: Schematic representation of the reliability criteria set out by Kuppra [26]. 


\section{Tables}

Table 1: Summary of the elevated temperature SHS and RHS column tests.

\begin{tabular}{|c|c|c|c|c|c|c|}
\hline Specimen reference & Reference & Grade & Boundary condition & $L(\mathrm{~mm})$ & Load $(\mathrm{kN})$ & $\theta_{\text {crit }}\left({ }^{\circ} \mathrm{C}\right)$ \\
\hline SHS $80 \times 80 \times 3-3000$ & \multirow{3}{*}[1]{} & \multirow{3}{*}{$\begin{array}{c}\text { Ferritic } \\
\text { EN } 1.4003\end{array}$} & \multirow{3}{*}{ Fixed } & 3000 & 72 & $709^{*}$ \\
\hline SHS $80 \times 80 \times 3-2500$ & & & & 2500 & 78 & $708^{*}$ \\
\hline RHS $120 \times 80 \times 3-2500$ & & & & 2500 & 100 & $705^{*}$ \\
\hline SHS $40 \times 40 \times 4-T 1$ & \multirow{6}{*}[10]{} & \multirow{6}{*}{$\begin{array}{l}\text { Austenitic } \\
\text { EN 1.4301 }\end{array}$} & \multirow{6}{*}{ Pinned } & 888.5 & 45 & 872 \\
\hline SHS $40 \times 40 \times 4-T 2$ & & & & 888.5 & 129 & 579 \\
\hline SHS $40 \times 40 \times 4-T 3$ & & & & 888.0 & 114 & 649 \\
\hline SHS $40 \times 40 \times 4-T 4$ & & & & 888.0 & 95 & 710 \\
\hline SHS $40 \times 40 \times 4-T 5$ & & & & 888.0 & 55 & 832 \\
\hline SHS $40 \times 40 \times 4-T 7$ & & & & 888.5 & 75 & 766 \\
\hline RHS $150 \times 100 \times 6$ & \multirow{3}{*}[11]{} & \multirow{3}{*}{$\begin{array}{l}\text { Austenitic } \\
\text { EN 1.4301 }\end{array}$} & \multirow{3}{*}{ Fixed } & 3400 & 268 & 801 \\
\hline RHS $150 \times 75 \times 6$ & & & & 3400 & 140 & 883 \\
\hline RHS $100 \times 75 \times 6$ & & & & 3400 & 156 & 806 \\
\hline
\end{tabular}

* Critical furnace temperature

Table 2: Summary of the room temperature CHS column tests.

\begin{tabular}{|c|c|c|c|c|c|}
\hline Specimen reference & Reference & Grade & Boundary condition & $L(\mathrm{~mm})$ & $N_{u}(\mathrm{kN})$ \\
\hline $\begin{array}{l}\text { CHS } 60.5 \times 2.8 \\
\text { CHS } 76.3 \times 3\end{array}$ & [12] & $\begin{array}{l}\text { Austenitic } \\
\text { EN 1.4301 }\end{array}$ & Pinned & $\begin{array}{l}1450 \\
1450\end{array}$ & $\begin{array}{c}90.5 \\
146.0\end{array}$ \\
\hline $\begin{array}{l}\text { CHS } 106 \times 3-550 \\
\text { CHS } 106 \times 3-1150 \\
\text { CHS } 106 \times 3-3080\end{array}$ & [13] & $\begin{array}{l}\text { Austenitic } \\
\text { EN } 1.4432\end{array}$ & Pinned & $\begin{array}{l}554.27 \\
1154.0 \\
3083.0\end{array}$ & $\begin{array}{l}267.0 \\
248.8 \\
150.8\end{array}$ \\
\hline $\begin{array}{l}\text { CHS } 88.9 \times 2.6-400 \\
\text { CHS } 88.9 \times 2.6-1650 \\
\text { CHS } 88.9 \times 2.6-3080\end{array}$ & [13] & $\begin{array}{c}\text { Duplex } \\
\text { EN } 1.4462\end{array}$ & Pinned & $\begin{array}{c}403.9 \\
1656.6 \\
3082.5\end{array}$ & $\begin{array}{l}425.2 \\
243.4 \\
100.5\end{array}$ \\
\hline $\begin{array}{l}\text { CHS } 80 \times 1.5-700 \\
\text { CHS } 80 \times 1.5-900 \\
\text { CHS } 80 \times 1.5-1600\end{array}$ & [13] & $\begin{array}{c}\text { Ferritic } \\
\text { EN } 1.4512\end{array}$ & Pinned & $\begin{array}{c}698.6 \\
899.1 \\
1599.3\end{array}$ & $\begin{array}{c}111.1 \\
105.8 \\
77.9\end{array}$ \\
\hline
\end{tabular}


Table 3: Comparison of test and FE critical temperature $\theta_{\text {crit }}$ for SHS/RHS columns.

\begin{tabular}{|c|c|c|c|}
\hline \multirow{2}{*}{ Specimen reference } & \multicolumn{3}{|c|}{$\theta_{\text {crit }}\left({ }^{\circ} \mathrm{C}\right)$} \\
\hline & Test & $\mathrm{FE}$ & FE/Test \\
\hline SHS $80 \times 80 \times 3-3000$ & 709 & 726 & 1.02 \\
\hline SHS $80 \times 80 \times 3-2500$ & 708 & 718 & 1.02 \\
\hline RHS $120 \times 80 \times 3-2500$ & 705 & 709 & 1.01 \\
\hline SHS $40 \times 40 \times 4-\mathrm{T} 1$ & 872 & 750 & 0.86 \\
\hline SHS $40 \times 40 \times 4-\mathrm{T} 2$ & 579 & 502 & 0.87 \\
\hline SHS $40 \times 40 \times 4-\mathrm{T} 3$ & 649 & 608 & 0.94 \\
\hline SHS $40 \times 40 \times 4-\mathrm{T} 4$ & 710 & 646 & 0.91 \\
\hline SHS $40 \times 40 \times 4-T 5$ & 832 & 722 & 0.87 \\
\hline SHS $40 \times 40 \times 4-T 7$ & 766 & 681 & 0.89 \\
\hline RHS $150 \times 100 \times 6$ & 801 & 757 & 0.91 \\
\hline RHS $150 \times 75 \times 6$ & 883 & 814 & 0.92 \\
\hline RHS $100 \times 75 \times 6$ & 806 & 744 & 0.92 \\
\hline
\end{tabular}

Table 4: Comparison of test and FE ultimate load $\mathrm{N}_{u}$ and displacement at ultimate load $\delta_{u}$ for CHS columns.

\begin{tabular}{|c|c|c|c|c|c|c|}
\hline \multirow{2}{*}{ Specimen reference } & \multicolumn{3}{|c|}{$N_{\mathrm{u}}(\mathrm{kN})$} & \multicolumn{3}{|c|}{$\delta_{\mathrm{u}}(\mathrm{mm})$} \\
\hline & Test & $\mathrm{FE}$ & FE/Test & Test & FE & $\mathrm{FE} /$ Test \\
\hline CHS $60.5 \times 2.8$ & 90.5 & 89.6 & 0.99 & 6.4 & 10.0 & 1.56 \\
\hline CHS $76.3 \times 3$ & 146.0 & 144.7 & 0.99 & 4.1 & 5.4 & 1.32 \\
\hline CHS 106×3-550 & 267.0 & 285.5 & 1.07 & 7.7 & 2.3 & 0.30 \\
\hline CHS $106 \times 3-1150$ & 248.8 & 226.6 & 0.91 & 3.9 & 5.7 & 1.46 \\
\hline CHS 106×3-3080 & 150.8 & 144.4 & 0.96 & 10.9 & 6.9 & 0.63 \\
\hline CHS $88.9 \times 2.6-400$ & 425.2 & 418.4 & 0.98 & 2.9 & 2.2 & 0.76 \\
\hline CHS 88.9×2.6-1650 & 243.4 & 251.1 & 1.03 & 11.5 & 8.5 & 0.74 \\
\hline CHS 88.9×2.6-3080 & 100.5 & 106.5 & 1.06 & 25.8 & 34.4 & 1.33 \\
\hline CHS $80 \times 1.5-700$ & 111.1 & 116.5 & 1.05 & 3.3 & 1.8 & 0.55 \\
\hline CHS $80 \times 1.5-900$ & 105.8 & 108.5 & 1.03 & 3.8 & 2.6 & 0.68 \\
\hline CHS $80 \times 1.5-1600$ & 77.9 & 87.0 & 1.12 & 9.1 & 6.0 & 0.66 \\
\hline
\end{tabular}


Table 5: Summary of the parametric study variables.

\begin{tabular}{|c|c|c|c|c|c|c|c|}
\hline Section & Grade & Section & $h / b$ & Buckling axis & Temperatures & $\bar{\lambda}_{\mathrm{p}}$ or $\bar{\lambda}_{\mathrm{c}}$ & $\bar{\lambda}_{\theta}$ \\
\hline \multirow{6}{*}{ SHS/RHS } & A ustanitis & SHS $100 \times 100 \times 10$ & 1.0 & - & \multirow{6}{*}{$\begin{array}{c}200,400 \\
600 \text { and } \\
800\left({ }^{\circ} \mathrm{C}\right)\end{array}$} & 0.33 & \multirow{6}{*}{$0.1-2.0$} \\
\hline & Austemtic & RHS $150 \times 100 \times 14$ & 1.5 & Major and Minor & & 0.34 & \\
\hline & Dunlay & SHS $100 \times 100 \times 9$ & 1.0 & - & & 0.38 & \\
\hline & Duplex & RHS $150 \times 100 \times 14$ & 1.5 & Major and Minor & & 0.36 & \\
\hline & \multirow{2}{*}{ Ferritic } & SHS $100 \times 100 \times 9$ & 1.0 & - & & 0.32 & \\
\hline & & RHS $150 \times 100 \times 11$ & 1.5 & Major and Minor & & 0.39 & \\
\hline \multirow{3}{*}{ CHS } & Austenitic & CHS $100 \times 8$ & - & - & \multirow{3}{*}{$\begin{array}{c}200,400, \\
600 \text { and } \\
800\left({ }^{\circ} \mathrm{C}\right)\end{array}$} & 0.18 & \multirow{3}{*}{$0.1-2.0$} \\
\hline & Duplex & CHS $100 \times 8$ & - & - & & 0.19 & \\
\hline & Ferritic & CHS $100 \times 8$ & - & - & & 0.16 & \\
\hline
\end{tabular}

Table 6: Room temperature material properties adopted in the parametric models.

\begin{tabular}{l|l|c|c|c|c|c}
\hline Grade & Section & $E\left(\mathrm{~N} / \mathrm{mm}^{2}\right)$ & $f_{0.2}\left(\mathrm{~N} / \mathrm{mm}^{2}\right)$ & $f_{2}\left(\mathrm{~N} / \mathrm{mm}^{2}\right)$ & $f_{\mathrm{u}}\left(\mathrm{N} / \mathrm{mm}^{2}\right)$ & $n$ \\
\hline Austenitic & SHS/RHS (F), CHS & 200000 & 460 & 603 & 700 & 2.9 \\
Duplex & SHS/RHS (F), CHS & 200000 & 630 & 706 & 780 & 4.8 \\
Ferritic & SHS/RHS (F), CHS & 200000 & 430 & 490 & 490 & 4.6 \\
Austenitic & SHS/RHS (C) & 200000 & 640 & 838 & 830 & 7.1 \\
Duplex & SHS/RHS (C) & 200000 & 800 & 896 & 980 & 6.7 \\
Ferritic & SHS/RHS (C) & 200000 & 560 & 610 & 610 & 6.8 \\
\hline
\end{tabular}

$\mathrm{F}=$ Flat face, $\mathrm{C}=$ Corner region 
Table 7: Comparison between the FE and predicted resistances.

\begin{tabular}{|c|c|c|c|c|c|}
\hline Section & Material & $N_{\mathrm{u}, \mathrm{FE}} / N_{\mathrm{u}, \text { predicted }}$ & EN 1993-1-2 & DMSS & $\begin{array}{l}\text { Proposed (Lopes } \\
\text { et al. extended) }\end{array}$ \\
\hline \multirow{15}{*}{ SHS/RHS } & \multirow{5}{*}{ Austenitic } & No. & 156 & 156 & 156 \\
\hline & & Mean & 0.897 & 1.049 & 1.114 \\
\hline & & $\mathrm{COV}$ & 0.118 & 0.138 & 0.062 \\
\hline & & $\operatorname{Max}$ & 1.157 & 1.574 & 1.256 \\
\hline & & Min & 0.682 & 0.844 & 0.965 \\
\hline & \multirow{5}{*}{ Duplex } & No. & 160 & 160 & 160 \\
\hline & & Mean & 0.915 & 1.036 & 1.047 \\
\hline & & $\mathrm{COV}$ & 0.136 & 0.127 & 0.060 \\
\hline & & $\operatorname{Max}$ & 1.212 & 1.534 & 1.275 \\
\hline & & Min & 0.649 & 0.806 & 0.887 \\
\hline & \multirow{5}{*}{ Ferritic } & No. & 188 & 188 & 188 \\
\hline & & Mean & 1.029 & 1.043 & 1.069 \\
\hline & & $\mathrm{COV}$ & 0.091 & 0.071 & 0.056 \\
\hline & & $\operatorname{Max}$ & 1.166 & 1.231 & 1.177 \\
\hline & & Min & 0.801 & 0.888 & 0.925 \\
\hline \multirow{15}{*}{ CHS } & \multirow{5}{*}{ Austenitic } & No. & 50 & 50 & 50 \\
\hline & & Mean & 0.910 & 1.047 & 1.051 \\
\hline & & $\mathrm{COV}$ & 0.108 & 0.094 & 0.054 \\
\hline & & $\operatorname{Max}$ & 1.060 & 1.392 & 1.158 \\
\hline & & Min & 0.749 & 0.895 & 0.942 \\
\hline & \multirow{5}{*}{ Duplex } & No. & 50 & 50 & 50 \\
\hline & & Mean & 0.930 & 1.055 & 1.095 \\
\hline & & $\mathrm{COV}$ & 0.119 & 0.083 & 0.055 \\
\hline & & $\operatorname{Max}$ & 1.085 & 1.250 & 1.191 \\
\hline & & Min & 0.696 & 0.865 & 0.959 \\
\hline & \multirow{5}{*}{ Ferritic } & No. & 56 & 56 & 56 \\
\hline & & Mean & 1.085 & 1.049 & 1.081 \\
\hline & & COV & 0.063 & 0.082 & 0.066 \\
\hline & & Max & 1.216 & 1.200 & 1.197 \\
\hline & & Min & 0.966 & 0.901 & 0.960 \\
\hline
\end{tabular}

Table 8: Proposed $\beta$ and $\eta$ parameters for cold-formed SHS, RHS and CHS columns.

\begin{tabular}{ccccccc}
\hline & \multicolumn{3}{c}{ SHS/RHS } & \multicolumn{3}{c}{ CHS } \\
\cline { 2 - 7 } & Austenitic & Duplex & Ferritic & Austenitic & Duplex & Ferritic \\
\hline$\beta$ & 0.8 & 0.8 & 1.0 & 0.7 & 0.8 & 1.0 \\
\hline$\eta$ & 1.5 & 1.1 & 0.6 & 1.3 & 1.2 & 0.5 \\
\hline
\end{tabular}


Table 9: Summary of the reliability assessment results.

\begin{tabular}{|c|c|c|c|c|c|c|c|c|}
\hline \multirow[t]{2}{*}{ Section } & \multirow[t]{2}{*}{ Material } & \multirow{2}{*}{$\begin{array}{l}\text { Criterion } \\
\text { Criterion } 1\end{array}$} & \multicolumn{2}{|c|}{ EN 1993-1-2 } & \multicolumn{2}{|c|}{ DMSS } & \multicolumn{2}{|c|}{$\begin{array}{l}\text { Proposed (Lopes et } \\
\text { al. extended) }\end{array}$} \\
\hline & & & $41.7 \%$ & Fail & $5.1 \%$ & Fail & $0.0 \%$ & Pass \\
\hline \multirow{8}{*}{ SHS/RHS } & Austenitic & Criterion 2 & $76.9 \%$ & Fail & $41.7 \%$ & Fail & $7.7 \%$ & Pass \\
\hline & & Criterion 3 & 0.131 & Fail & -0.032 & Pass & -0.099 & Pass \\
\hline & & Criterion 1 & $30.0 \%$ & Fail & $11.9 \%$ & Fail & $0.0 \%$ & Pass \\
\hline & Duplex & Criterion 2 & $70.0 \%$ & Fail & $35.0 \%$ & Fail & $15.0 \%$ & Pass \\
\hline & & Criterion 3 & 0.115 & Fail & -0.020 & Pass & -0.041 & Pass \\
\hline & & Criterion 1 & $9.0 \%$ & Fail & $0.0 \%$ & Pass & $0.0 \%$ & Pass \\
\hline & Ferritic & Criterion 2 & $31.9 \%$ & Fail & $30.9 \%$ & Fail & $12.2 \%$ & Pass \\
\hline & & Criterion 3 & -0.019 & Pass & -0.036 & Pass & -0.062 & Pass \\
\hline \multirow{9}{*}{$\mathrm{CHS}$} & & Criterion 1 & $40.0 \%$ & Fail & $0.0 \%$ & Pass & $0.0 \%$ & Pass \\
\hline & Austenitic & Criterion 2 & $76.0 \%$ & Fail & $34.0 \%$ & Fail & $20.0 \%$ & Pass \\
\hline & & Criterion 3 & 0.112 & Fail & -0.037 & Pass & -0.046 & Pass \\
\hline & & Criterion 1 & $26.0 \%$ & Fail & $2.0 \%$ & Fail & $0.0 \%$ & Pass \\
\hline & Duplex & Criterion 2 & $70.0 \%$ & Fail & $26.0 \%$ & Fail & $8.0 \%$ & Pass \\
\hline & & Criterion 3 & 0.092 & Fail & -0.045 & Pass & -0.084 & Pass \\
\hline & & Criterion 1 & $0.0 \%$ & Pass & $0.0 \%$ & Pass & $0.0 \%$ & Pass \\
\hline & Ferritic & Criterion 2 & $8.9 \%$ & Pass & $28.6 \%$ & Fail & $16.1 \%$ & Pass \\
\hline & & Criterion 3 & -0.075 & Pass & -0.040 & Pass & -0.071 & Pass \\
\hline
\end{tabular}

